\title{
El balneum oriental del castellum tingitano de Tamuda. Estudio arqueo-arquitectónico y propuesta de valorización*
}

\section{The Eastern Balneum of the castellum of Tamuda in Tingitana. Archaeo-architectural research and valuation proposal}

\author{
José Ángel Expósito Álvarez ${ }^{1}$ \\ Conjunto Arqueológico de Baelo Claudia \\ Darío Bernal-Casasola² \\ Universidad de Cádiz \\ Javier Verdugo Santos ${ }^{3}$ \\ Arqueólogo Conservador de Patrimonio \\ Francisco J. Ramón Girón ${ }^{4}$ \\ Arquitecto Conservador de Patrimonio \\ Tarik Moujoud ${ }^{5}$ \\ Site Archéologique de Tamuda
}

\begin{abstract}
RESUMEN
En este trabajo nos acercamos a la arquitectura del balneum descubierto en el barrio oriental del campamento romano de Tamuda (Tetuán, Marruecos), el cual posiblemente es el principal edificio de baños del asentamiento. Para realizar este estudio, hemos unificado los resultados derivados del análisis arqueo-arquitectónico con fotogrametría y levantamientos volumétricos, de manera que se ofrece una propuesta de articulación espacial. Esta responde a todos los elementos arquitectónicos identificados y a los contextos recuperados a través de su excavación. El resultado es una propuesta interpretativa que da sentido a los espacios y recorridos interiores y de levantamiento volumétrico, ambos coherentes con los paralelos identificados y con las estructuras descubiertas, que permiten acercarnos de manera más clara a la realidad del principal balneum del campamento. Como complemento, se ha incorporado una propuesta de valorización actual que conlleva la protección del edificio y su inserción en un circuito de visitas ad hoc.
\end{abstract}

Palabras clave: termas romanas; Mauretania Tingitana; hypocaustum; apodyterium; praefurnium; caldarium; cannabae.

\section{ABSTRACT}

In this paper we approach the architecture of the balneum discovered in the eastern quarter next to the Roman fort of Tamuda (Tetouan, Morocco), which are probably the main baths of the settlement. To carry out this study, we have unified the results derived from the archaeo-architectural analysis with photogrammetry and volumetric surveys, so it has been possible to propose a spatial articulation. This one responds to all the identified architectural elements and the contexts recovered through their excavation. The result is an interpretative proposal that

Estos trabajos se han realizado en el marco de desarrollo del Convenio de Colaboración entre la Direction du Patrimoine del Ministerio de Cultura de Marruecos y la Universidad de Cádiz (2017-2019); del programa de Ayudas a Proyectos Arqueológicos en el Exterior del Ministerio de Cultura y Deporte (convocatorias de 2017 a 2019), y de las Ayudas a Misiones en Arqueología y Paleontología Humana Españolas en el extranjero de la Fundación PALARQ (Convocatorias de 2018 y 2019); Además, esta publicación es resultado y ha sido cofinanciado por el proyecto GARVM III (PID2019-108948RB-I00/ AEI / 10.13039/501100011033) del Gobierno de España/Feder; por el Programa Operativo FEDER 2014-2020 y por la Consejería de Economía, Conocimiento, Empresas y Universidad de la Junta de Andalucía (referencia del proyecto: ARQUEOSTRA, FEDER-UCA18-104415); y por el proyecto ARQUEOFISH (P18FR-1483) del Programa de Ayudas a la I+D+i del Plan Andaluz de Investigación, Desarrollo e Innovación (PAIDI 2020). Los autores firmantes del texto son también autores de las figuras, salvo que se cite expresamente en el pie de figuras correspondiente.

josea.exposito@juntadeandalucia.es / ORCID iD: https://orcid.org/0000-0003-2997-6165

dario.bernal@uca.es / ORCID iD: https://orcid.org/0000-0003-1107-5318

fjavier.verdugo@gmail.com / ORCID iD: https://orcid.org/0000-0003-3641-3117

fjose.ramon@gmail.com / ORCID iD: https://orcid.org/0000-0003-1876-1820

tarikmoujoud@gmail.com / ORCID iD: https://orcid.org/0000-0002-8433-3261 
explains the spaces and their internal routes and that offers a volumetric survey, both of them according to the parallels identified and to the discovered structures. This output allows us to properly approach the reality of the main balneum of the Roman fort. We have besides incorporated a current valorization proposal that entails the protection of the building and its integration within a circuit of visits designed ad hoc.

Key words: Roman baths; Mauretania Tingitana; hypocaustum; apodyterium; praefurnium; caldarium; cannabae.

Recibido: 12-10-2020. Aceptado: 10-12-2020. Publicado: 01-06-2021

\section{Cómo citar este artículo / Citation}

Expósito, J. A., Bernal-Casasola, D., Verdugo, J., Ramón Girón, F. J. y Moujoud, T. 2021: "El balneum oriental del castellum tingitano de Tamuda. Estudio arqueo-arquitectónico y propuesta de valorización", Arqueología de la Arquitectura, 18: e119. https://doi.org/10.3989/arq.arqt.2021.011

Copyright: (C) CSIC, 2021. (C) UPV/EHU Press, 2021. Este es un artículo de acceso abierto distribuido bajo los términos de la licencia de uso y distribución Creative Commons Reconocimiento 4.0 Internacional (CC BY 4.0).

\section{INTRODUCCIÓN}

El yacimiento arqueológico de Tamuda se sitúa a las afueras de Tetuán y a orillas del río Martil, erigiéndose como uno de los enclaves arqueológicos más importantes del norte de Marruecos (Figs. 1 y 2). El castellum que vertebra este yacimiento representa un ejemplo emblemático de las fortificaciones erigidas en el limes meridional del mundo romano y de su relación con los ferocissimi Mauritaniae populi controlados por Roma desde su establecimiento en el s. I d. C., sobre un asentamiento previo mauritano, hasta su abandono en la primera mitad del s. V d. C. asociado al desmembramiento de las estructuras organizativas del Imperio. El castellum tamudense se define como un punto estratégico de gran importancia asociado a la defensa frente a las poblaciones del Rif y a la accesibilidad que ofrecía su conexión por mar mediante la navegabilidad que brindaba el río Martil en la Antigüedad. En el contexto de ocupación del castellum es en el que se enmarca el edificio balneario que analizamos, que fue identificado y excavado por un equipo marroco-español de la Universidad Abdelmalek Essâadi, la Direction du Patrimoine del Ministerio de Cultura de Marruecos y la Universidad de Cádiz entre 2012 y 2018, y que se corresponde con un balneum levantado en el barrio oriental surgido extra moenia de la fortificación al amparo de la consolidación del asentamiento militar, para dar servicio a las tropas acantonadas en él, y probablemente asociado al desarrollo de otros equipamientos que vertebrarían las cannabae o vicus militar surgido al amparo del castellum.

El estudio de este edificio se enmarca dentro de los trabajos del proyecto de investigación Economía y Ar-

A

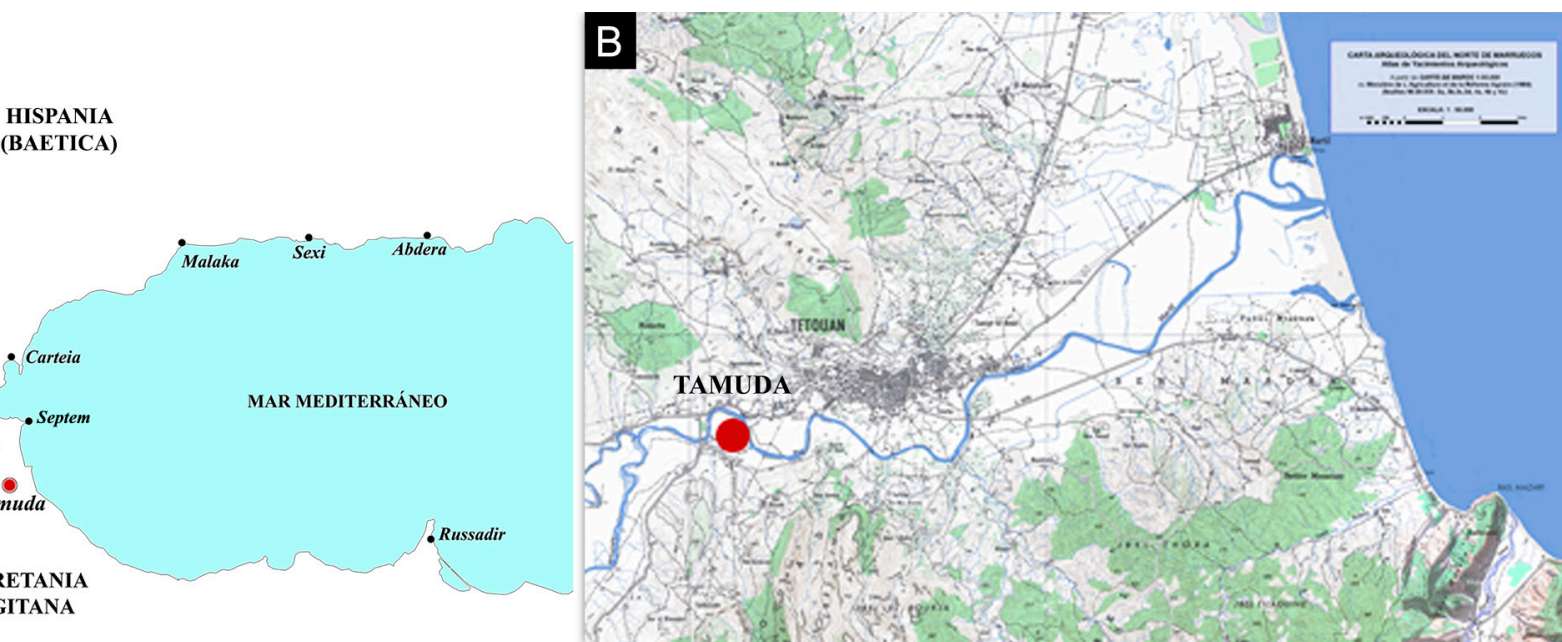

Figura 1. Localización del yacimiento mauritano de Tamuda y del balneum del barrio oriental. Plano del Estrecho de Gibraltar con las principales ciudades antiguas (A); localización planimétrica de Tamuda junto al río Martil y contigua a la ciudad actual de Tetuán (B). 
A
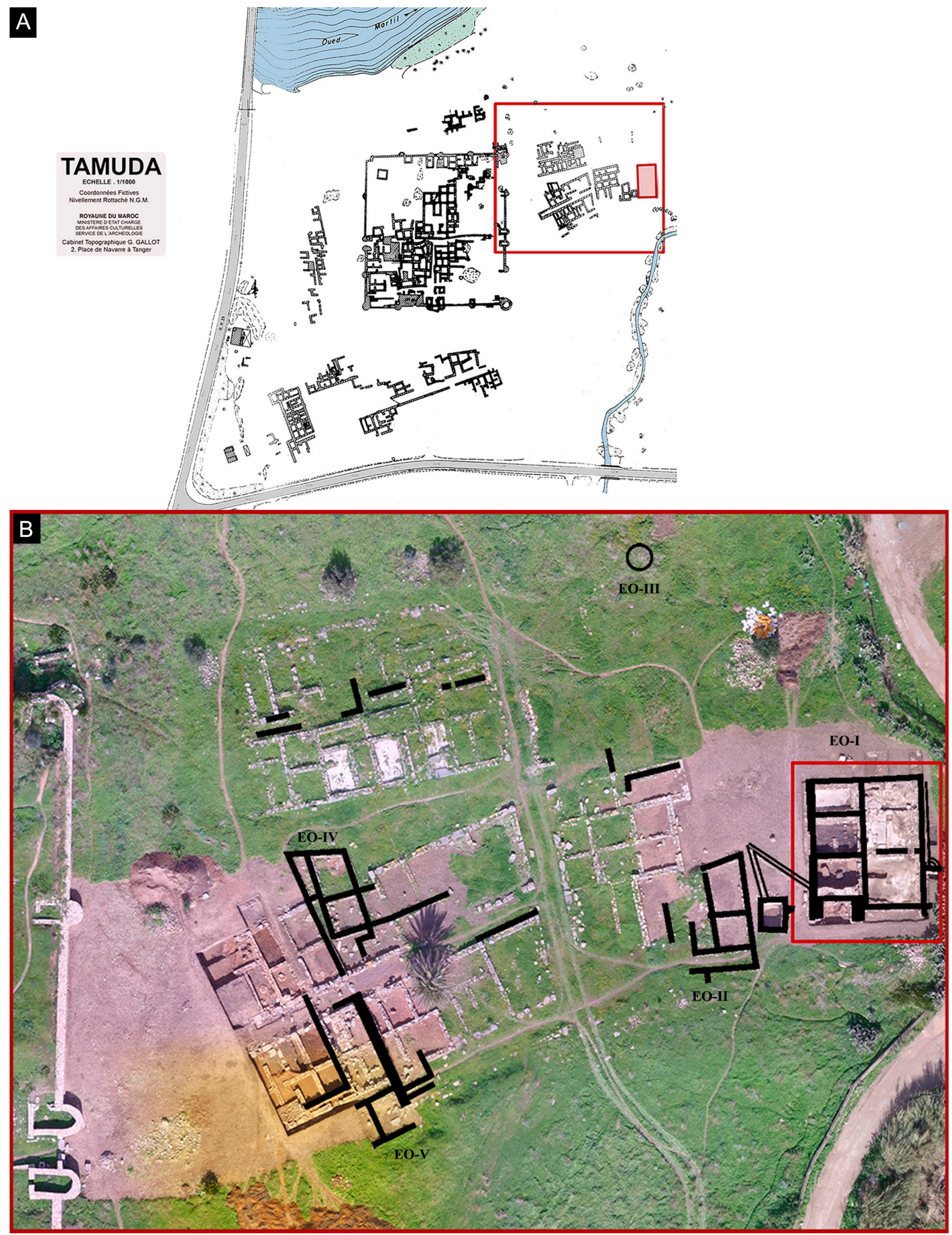

Figura 2. Planimetría del yacimiento mauritano con indicación (en rojo) del barrio oriental y del emplazamiento del balneum. (A) Detalle del barrio oriental con la ubicación del balneum (EO-I) y las estructuras romanas descubiertas con la correspondiente nomenclatura aplicada a las mismas (B). 
tesanado en Tamuda, desarrollado por la Universidad de Cádiz entre 2014 y 2019 y centrado en la recuperación del barrio oriental, que se trataba de una de las zonas peor conocidas del yacimiento. Sus resultados han puesto sobre la mesa importantes novedades en torno al asentamiento mauritano, al sistema defensivo del castellum, y a los equipamientos auxiliares de la fortificación erigidos en su entorno, correspondientes al menos con espacios de estabulación, áreas de actividades artesanales e instalaciones de ocio e higiene, como las que aquí presentamos (Bernal-Casasola et al. 2019: 188-190, fig. 7B), lo que nos ha permitido empezar a aproximarnos a la importancia del vicus que se articularía en el entorno del campamento militar.

El balneum que analizamos se corresponde sin ninguna duda con un equipamiento de gran interés arquitectónico que además se trata del edificio romano de mayor entidad documentado fuera de las murallas del castellum, por lo que su excavación, el estudio arqueo-arquitectónico y el proyecto de puesta en valor que presentamos cobra una especial significación para la comprensión y la dinamización patrimonial del yacimiento. No es el único balneum conocido en Tamuda, ya que en lo que respecta a la presencia de equipamientos destinados a la higiene de las tropas, se había identificado un primer pequeño edificio termal localizado al abrigo de las murallas, cerca de la Porta Praetoria, si bien su escasa talla y su posible vinculación con la presencia de un valetudinarum contiguo (Campos et al. 2012) imposibilitaban el hecho de que se tratase del principal edificio termal del asentamiento, que ahora sí podemos identificar con mayor claridad.

\section{EXCAVACIÓN Y DATACIÓN DEL EDIFI- CIO TERMAL}

Los trabajos que se desarrollaron en Tamuda a partir de 1944, y especialmente en la década siguiente, sacaron a la luz buena parte de las estructuras hoy visibles del citado barrio oriental, si bien quedó sin excavar el extremo más oriental del yacimiento, donde solo se identificó en 1944 la presencia de una pileta vinculada con el acopio hídrico (Quintero y Giménez 1945: 10-11; Morán y Giménez 1948: lám. IVa). Los trabajos desarrollados desde 2012 en este sector permitieron confirmar su asociación con un nuevo edificio termal que pudimos finalizar de exhumar completamente en 2018.
Las excavaciones arqueológicas llevadas a cabo en las sucesivas campañas, sobre las cuales ya hemos presentado unas primeras aproximaciones (Bernal-Casasola et al. 2016; 2018a; 2018b; 2019), comenzaron en 2012 con la primera identificación del edificio termal, al constatarse la presencia de la hipocausis y la bañera de una sala calefactada, así como varias pavimentaciones hidráulicas asociadas. La siguiente campaña de excavación se desarrolló dos años después, en 2014, ampliándose el área de intervención con el objetivo de concretar la funcionalidad y superficie ocupada por las salas identificadas, de manera que se pudo delimitar la mitad meridional del edificio y descubrir un nuevo ambiente al norte del mismo, a la vez que se pudieron exhumar las primeras evidencias de remodelaciones, protagonizadas por un horno excavado cortando la pavimentación hidráulica de una sala fría. La campaña de 2015 sirvió para recuperar el apodyterium y ampliar el conocimiento sobre los espacios de servicio situados al sur y este del edificio. En 2016 se excavó la piscina fría localizada al noroeste del edificio, y se finalizó la recuperación del apodyterium y las canalizaciones descubiertas en el sector oriental. Por último, entre 2017 y 2018 se excavaron las estancias calefactadas y el propnigeum principal (Bernal-Casasola et al. 2018a: fig. 2), finalizando la última campaña con la realización de un detallado análisis arqueo-arquitectónico del edificio, ya completo, que nos permitiese afrontar la propuesta interpretativa y reconstructiva que presentamos aquí.

En lo que respecta a las fases identificadas de fundación, uso y amortización del edificio termal, a la hora de establecer su marco de datación, hemos podido apoyarnos en los datos aportados por los registros materiales, que han sido generosos a nivel mueble e inmueble, y que han permitido fechar la construcción del edificio en el segundo cuarto del s. II d. C., durante el gobierno del emperador Adriano, gracias a la presencia de materiales de estos momentos entre los contextos estratigráficos (sigillata africana de la forma Hayes 8) y constructivos (como la presencia de ARSW A integrada en pavimentaciones de opus signinum de una de las salas calefactadas). Sin embargo, los datos más clarividentes al respecto se obtuvieron gracias al uso, como materia prima destinada a la sujeción de las placas de concamerationes, de pilas de ladrillos con escotadura (o de "camiseta"), que se integraban en los muros perimetrales de las salas calefactadas, los cuales se pudieron identificar como procedentes de talleres imperiales, ya que conservaban sus sellos identificativos (en este caso 
IMP AVG, HADRI AVG y ANTO AVG). Esta característica nos permitió fechar con claridad su construcción en época adrianea (117-138 d. C.) pero además nos sirvió para asociar la producción conjunta de estos sellos que se vinculan en todos los casos a figlinae locales o regionales (¿del entorno de Tingis?), como ya hemos defendido in extenso en trabajos anteriores (Bernal-Casasola et al. 2016: 143-144).

Disponemos, igualmente, de testimonios que nos permiten confirmar que el edificio fue objeto de diferentes reformas y readaptaciones de espacios, que implicaron la modificación del circuito termal y el cambio de funcionalidad de algunos ambientes que se produjeron a lo largo de la vida útil del balneum, principalmente derivados de la inserción de dos nuevos hornos calefactores; si bien el testimonio más sobresaliente en lo referente a las modificaciones constatadas, por su significación histórica y relevancia patrimonial, fue la localización de una inscripción lapídea que fue hallada reutilizada como parte de la tapa de una canalización de desagüe de la piscina, y cuyo texto hacía referencia a la conmemoración de una victoria militar que habría tenido lugar a finales del s. III o inicios del IV si atendemos al contexto del hallazgo y a su paleografía (Bernal-Casasola et al. 2016; 2018b), que recientemente otros investigadores prefieren situar en la primera mitad del s. III (Bernard 2020: 352-353). Este descubrimiento sirve como recordatorio de que, con posterioridad a estos momentos, el edificio termal siguió en uso, siendo objeto de reformas interiores con el objetivo de prolongar su vida útil y adaptarse a las posiblemente cambiantes necesidades de sus usuarios, como sucede en el balneum del castellum de Bothwellhaugh (Lanarkshire, Escocia), donde también se encontró una inscripción conmemorativa reutilizada en el frigidarium (Keppie 1981: 49).

En lo que se refiere al cese de actividad del balneum, constatamos que se lleva a cabo en la primera mitad del s. V d. C., a la par que el abandono del campamento. De nuevo los contextos materiales son claros al respecto, en virtud de los registros estratigráficos que presentan cerámicas a torno lento acompañadas de importaciones de vajillas de mesa africanas ARSW-D, como la forma Hayes 91a (Bernal-Casasola et al. 2016: 144) y contextos anfóricos afines (Keay 35 ), pero especialmente concretados gracias a los numerosos registros monetales depositados sobre las pavimentaciones, debiendo destacar en este sentido la presencia de una ocultación monetal de más de 60 piezas, localizada bajo uno de los arcos que conectan las hipocausis de las salas calefactadas, monedas entre las que se podían observar emisiones de Honorio, en sintonía con las tesis propuestas.

\section{ARQUITECTURA Y USO DEL EDIFICIO TERMAL}

\section{Análisis arqueo-arquitectónico}

Los trabajos desarrollados han permitido confirmar que el inmueble que analizamos se trata de un complejo termal definido por un gran edificio exento de 224 $\mathrm{m}^{2}(14 \times 16 \mathrm{~m})$, al que habría que sumar los espacios de servicio situados al sur, este y oeste del mismo, los primeros adosados y los demás -exteriores- posiblemente porticados al menos en lo que respecta a los orientales. El edificio principal evidencia una composición cuadrangular y una orientación bien definida siguiendo los ejes cardinales, en sintonía urbanística con el castellum. En relación con su estructuración interna se identifican 6 ambientes y una piscina, localizándose las salas calientes al oeste, junto con el horno principal, como es habitual en otros edificios termales análogos (Reis 2004: 41), para aprovechar al máximo la insolación directa ya que esta orientación recibe radiación todo el año, desde el mediodía hasta el anochecer, de manera que puede ser aprovechada para implementar la calefacción de las salas. Las estancias frías, por tanto, quedarían circunscritas mayoritariamente al ala oriental, a excepción de la piscina (P-3), que se integra en el sector noroeste. Los ambientes identificados en el inmueble se corresponden con el apodyterium/frigidarium (ambiente 3), el tepidarium (ambiente 6), el caldarium (ambiente 1), y el propnigeum (ambiente 5), además de una sala fría ¿unctorium? (ambiente 2), y otros espacios de servicio (ambiente 4), si bien a lo largo de la vida útil del edificio creemos que el posible unctorium (ambiente 2) cesaría en su uso, pasando a convertirse en espacio de servicio y combustión, asumiendo el apodyterium/frigidarium o el tepidarium sus funciones esenciales (Fig. 3). En lo que respecta a su exterior, está pavimentado perimetralmente con un tosco mortero hidráulico, al menos en lo que respecta a la mitad noreste, donde desembocan los sistemas de desagües y algunas canalizaciones que tal vez se relacionen con la presencia de las letrinas. En el extremo contrario, 

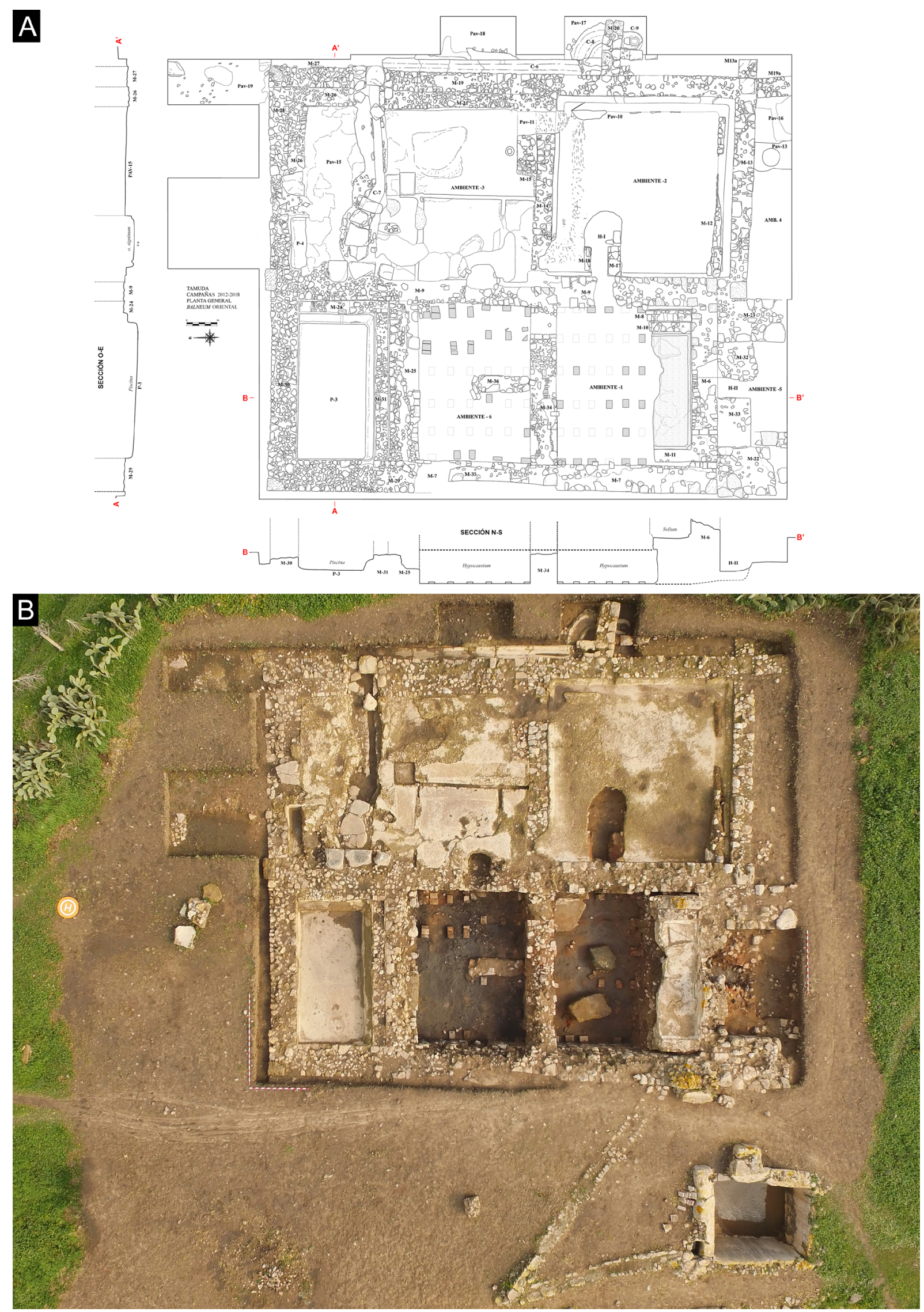

Figura 3. Balneum del barrio oriental de Tamuda. Planta (A) y fotografía cenital mediante vuelo drone (B). 
al suroeste, se localiza un depósito de agua abierto y exento que era alimentado, al igual que el balneum, a través de un ramal bifurcado del posible acueducto que llegaría también hasta el mismo edificio por este lateral, adentrándose en el mismo coincidiendo con el lugar donde se emplaza el alveus del caldarium.

Desde un punto de vista general, y atendiendo a sus acabados, observamos que el balneum responde a un modelo austero aunque funcional, dentro de lo que representan este tipo de edificios en el mundo romano, ya que por un lado no se observan evidencias de haber contado con acabados suntuosos como mármoles, mosaicos o pinturas murales, en lógica con su carácter castrense; mientras por otra parte, no renuncia a ninguno de los equipamientos característicos de este tipo de edificios. En esta línea de sobriedad arquitectónica, los muros maestros y medianeros están erigidos con alzados de mampuestos calizos irregulares a modo de pseudo-vittatum de baja calidad, prescindiendo del uso de una mampostería más elaborada, a excepción de los remates de los principales ejes murarios, donde sí observamos la presencia de bloques cuadrangulares de calcarenita; los pavimentos y revestimientos de piscinas, balsas y bañeras están acabados con opus signinum de distinto espesor y acabado, mientras para las pilae de las suspensurae, las paredes de las concamerationes y techumbres de las salas calefactadas se utilizó material latericio de factura local o regional, como ya hemos apuntado a partir de la lectura de sus sellos y tal y como apuntan macroscópicamente el aspecto jaspeado de sus pastas cerámicas, con múltiples desgrasantes de origen fluvial.

Adentrándonos en cada uno de los ambientes que definen el edificio, observamos en primer lugar que se caracterizan por conservarse con un nivel de arrasamiento de los alzados muy alto, que en general apenas se levantan unos centímetros sobre los niveles de uso, lo que dificulta su identificación funcional, si bien debemos apuntar que hay algunos sectores del inmueble, como la bañera del caldarium, donde el nivel de alzado supera $\operatorname{los} 70 \mathrm{~cm}$.

Retornando a la descripción interna, la entrada principal del edificio está situada en la cara norte, y viene marcada por la presencia de un umbral de 1,40 $\mathrm{cm}$ de anchura, que se encuentra mayoritariamente arrasado, pero del cual todavía se conserva una de las losas de caliza que remataba este acceso. Al flanquearlo observamos que nos adentramos en el eje de una estancia amplia y ligeramente alargada, de $8,2 \times$
6,2 m, que hemos identificado como el apodyterium o apodyterium/frigidarium (ambiente 3). Para su definición funcional contamos con la presencia de varios elementos canónicos que caracterizan a este tipo de salas anticipatorias de la secuencia termal.

\section{El apodyterium/frigidarium. El inicio del circuito termal}

En primer lugar, justo a la derecha una vez cruzado el umbral hacia su interior, en la esquina noroeste de la sala, observamos la presencia de una pequeña balsa (P-4) parcialmente amortizada por reformas posteriores, pero que todavía permite identificar su revestimiento interno de opus signinum de buena calidad que define unas dimensiones interiores de $1,7 \mathrm{~m}$ de longitud y $1,10 \mathrm{~m}$ de anchura si atendemos a las huellas visibles en el parcheado superior, no superando los 0,40 $\mathrm{m}$ de altura total $\left(0,44 \mathrm{~m}^{3}\right)$. Esta pileta debe tratarse de un pediluvium o pedilouve, un pequeño receptáculo hídrico situado a ras de suelo, destinado a la limpieza de los pies, que habitualmente se disponía junto a la puerta de entrada, como en nuestro caso, siendo especialmente común encontrarla en los primeros edificios termales (Fig. 4A). Este equipamiento, habitual en los apodyteria, es con posterioridad remplazado por el frigidarium (Nielsen 1993: vol. 1, 153), motivo por el cual posiblemente fue sellado tras las reformas llevadas a cabo, al caer en desuso esta práctica, como podemos observar en el balneum privado de $\mathrm{Sao} \mathrm{Cu}$ cufate, donde un pediluvium de similares dimensiones fue utilizado en las primeras fases para ser abandonado en época tardorromana (Reis 2004: 101-102). Atendiendo a esta evolución en el uso y al obstáculo que supone para el acceso a la piscina contigua, no podemos descartar que la vida útil de este receptáculo fuese muy breve, e incluso que respondiera a una fase primigenia en la cual la piscina no estuviese todavía en uso.

Uno de los elementos definitorios de los apodyteria o apodyteria/frigidaria a nivel arquitectónico es la presencia de bancos de asientos y/o nichos usados como zona de vestuario. A este respecto, en esta sala llama la atención la presencia de la cimentación de una estructura de 55-60 $\mathrm{cm}$ de ancho y una extensión total de 18,2 m (M-26/M21/M15), que se extiende en forma de "U", adosada al límite perimetral de toda la mitad oriental de la sala, partiendo desde el mismo margen de la puerta y desarrollándose con una sime- 

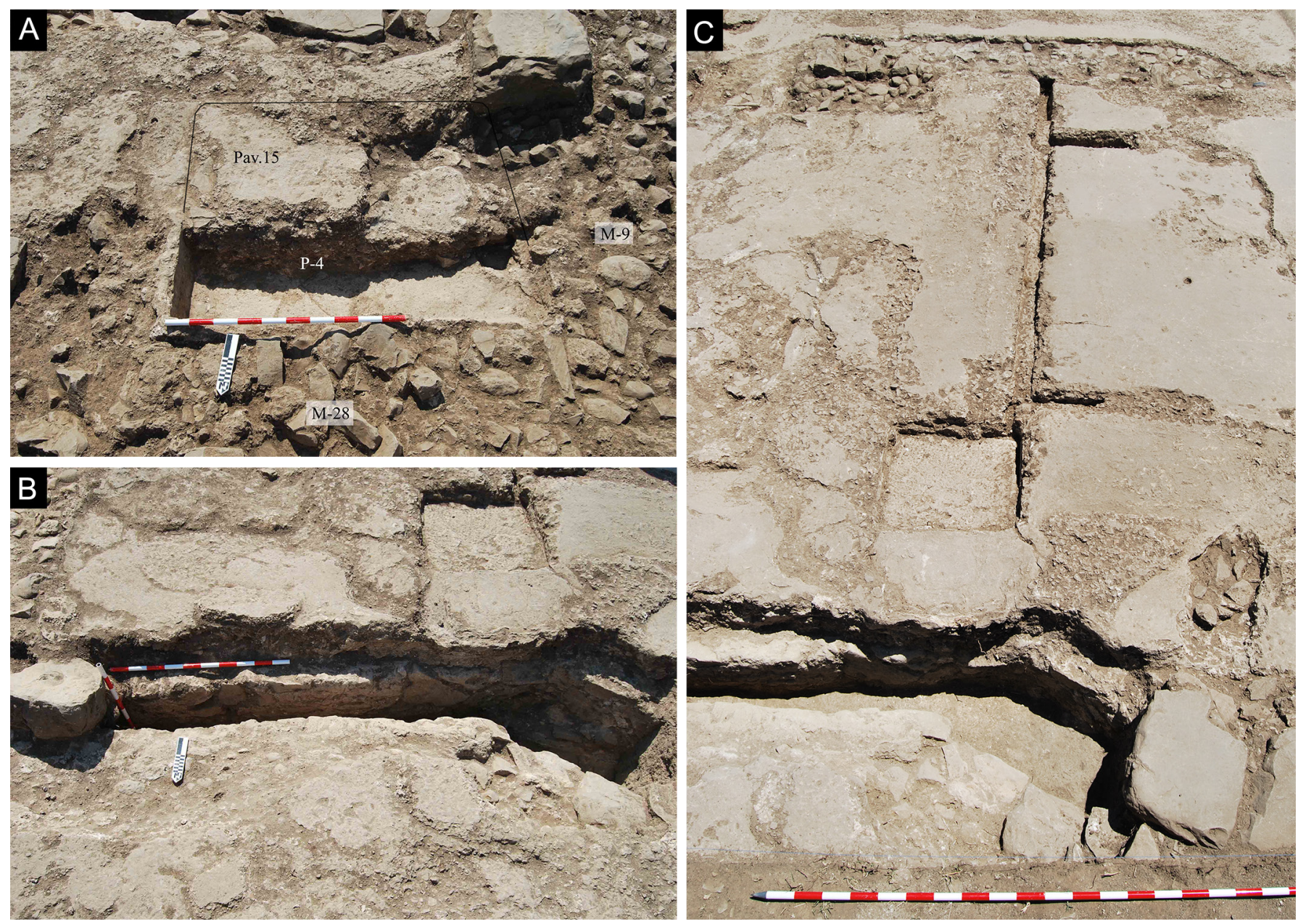

(A); vista general de la cloaca principal y la base para colocación de Figura 4. Elementos del apodyterium/frigidarium. Detalle del pedil
labrum o fuente (B) y detalle de las zanjas para las tuberías (C).

tría bien definida hasta el extremo contrario a modo de muro interior. Creemos que se trata de un banco corrido de mampostería que solo se ve alterado en su desarrollo por la presencia de la canalización de desagües, a la que cubriría, y una rotura fruto de la modificación de los accesos de la sala (Pav-11). Llama la atención su factura, ya que está realizada con mampuestos de menor talla que el muro perimetral, y en su matriz destaca tanto la ausencia de argamasa como el protagonismo de los cantos rodados, más abundantes que en el muro contiguo. Son notables los paralelos existentes de excelente conservación, como los apreciables en las Termas Estabianas de Pompeya o en las Termas Centrales de Herculano, por poner dos ejemplos especialmente representativos, si bien a menor escala y en ámbito hispano podemos traer a colación los bancos presentes en los apodyteria/frigidaria de los balnea de la villa de Can Tarrés y de la Casa de los Mármoles de Mérida (García-Entero 2005: 788), o en el apodyterium del Baño Fresco de Banasa, por poner algún ejemplo representativo dentro de la Tingitana (Nielsen 1993: vol. 2, fig. 123). El nivel de conservación actual impide hipotetizar sobre la presencia de estantes o nichos para colocar la ropa situados sobre dichos asientos, si bien es muy probable que dispusiese de dicho complemento contando con este banco de mampostería.

El elemento vertebrador de este ambiente es el agua, por la presencia de la piscina, que se abre al oeste de la sala, y por las huellas del sistema de fistulae aquariae que recorren este ambiente. En relación con este segundo aspecto, se observa en el eje de la estancia, la presencia de un surco de sección cuadrangular de apenas $10 \mathrm{~cm}$ de caja excavado en el pavimento de opus signinum, que recorre longitudinalmente la sala desde el extremo meridional hasta el centro de la misma, con 
dos ramales que se abren hacia el oeste (Fig. 4C), surcos que habrían servido para la inserción de una tubería de plomo destinada a surtir de agua a determinados servicios, como observamos en los baños de Vercovicium (Vega 2010: 314), si bien debemos apuntar que tras su expolio no hemos podido recuperar restos plúmbeos de dicha conducción. El ramal principal, atendiendo a las cotas del suelo, discurre de sur a norte, de manera que partiría de un tramo aéreo integrado en el muro de cierre meridional de la sala (M-14) para dirigirse hacia el norte hasta desembocar en un rebaje cuadrangular también excavado en el suelo de opus signinum, de $70 \times 75$ $\mathrm{cm}$ y $20 \mathrm{~cm}$ de potencia máxima, que asociamos con el encaje de alguna fuente o punto de agua, a modo de labrum, que fuese alimentado por la citada tubería (Fig. 4B). El excedente hídrico rebosaría superficialmente, hacia la pequeña cloaca situada inmediatamente al norte, ya que observamos la huella de una decantación constante de líquido en la superficie del suelo situado entre ambas estructuras, traducida en una rugosidad de su superficie, de manera que con lógica se reaprovechase para evacuar por el mismo desagüe el agua sobrante tanto de la piscina como de esta fuente. El receptáculo o encaje de este punto de agua se sitúa prácticamente en el centro de la sala y en el eje de la puerta de entrada, de manera que se visualizaría frontalmente al acceder a la sala en una localización protagonista bastante singular. Existen ejemplos de labra que se inscriben dentro de registros o arquetas como el que acabamos de describir (Morillo y Salido 2011: figs. 10 y 11), por lo que resultaría una estructura funcional y muy estética. No podemos descartar, por otra parte, que la estructura que se encajase en este hueco fuese un elemento escultórico con toma de agua, si bien dada la austeridad general del complejo termal, resulta más coherente decantarse por la primera opción, ya de por sí interesante desde un punto de vista ornamental. Los dos ramales que parten de la arteria principal que acabamos de describir se dirigen al oeste y se conservan todavía parcialmente cubiertos por la pavimentación, discurriendo hacia la conexión con el muro divisorio del tepidarium (ambiente 6). De estas dos bifurcaciones, el ramal más septentrional entronca con el extremo más cercano a la piscina P-3, por lo que, si bien de manera general, al igual que en el caso anterior, creemos que debieron servir para alimentar algún punto de agua situado en la sala calefactada contigua, no podemos descartar que en este caso también pudiera haber servido para el suministro de agua de la piscina contigua.

\section{La piscina frigidaria}

La piscina principal (P-3), a la que acabamos de hacer alusión, quedaba situada inmediatamente al oeste de esta sala, y con acceso directo desde la misma. Es un receptáculo hídrico rectangular (Fig. 5), con unas dimensiones totales $5,20 \times 2,95 \mathrm{~m}\left(15,3 \mathrm{~m}^{2}\right)$, incluyendo los dos escalones interiores perimetrales revestidos de opus signinum al este y sur, así como los muros situados a estos mismos lados que no conservan dicho revestimiento, pero que debieron disponer del mismo en origen (M-24 y M-31), los cuales tienen en ambos casos $42 \mathrm{~cm}$ de espesor, y se sitúa uno en el límite oriental (lado corto) y el otro en el meridional (extremo largo). La profundidad mínima conservada de la piscina es de $50 \mathrm{~cm}$, aunque sumando la altura escalonada del M-24 ascendería a los $80 \mathrm{~cm}$, si bien lo más probable es que dispusiese de un peldaño más a modo de rebosadero sobre M-9, que marcase el acceso desde el ambiente 3. Esta piscina frigidaria posiblemente fue objeto de una reforma en su interior, disponiendo originariamente de escalones solo
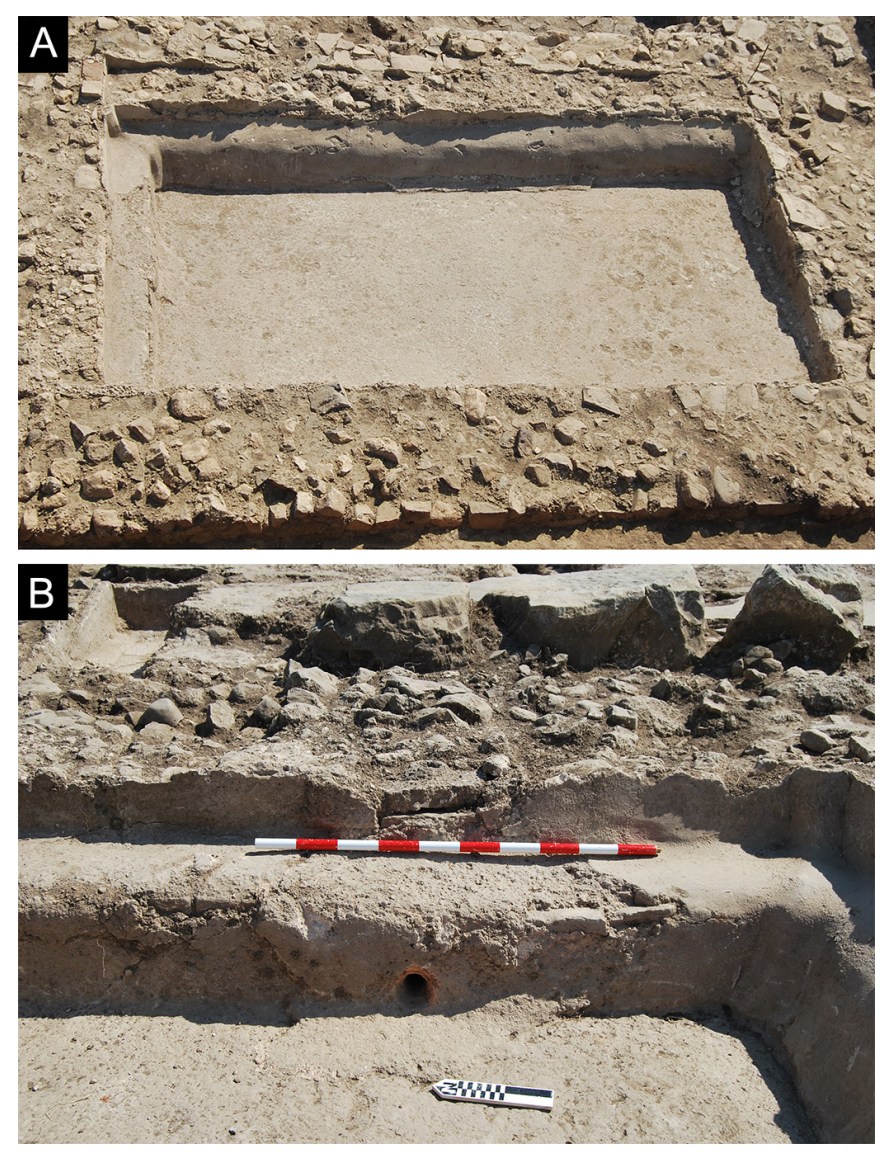

Figura 5. Piscina frigidaria. Vista aérea general desde el norte (A) y detalle del desagüe situado en la cabecera este (B). 
en el lado corto (oriental), coincidente con su acceso, como revela la huella de opus signinum observada en la unión entre M-24 y M-31. En referencia al sistema de desagües, advertimos que la balsa decanta hacia el este, donde se localiza el sumidero situado bajo los escalones, formado por una boca de ánfora, el cual abre el conducto hacia el desagüe principal que discurre bajo M-9 y recorre el apodyterium hacia poniente (Fig. 5B). Desconocemos la ubicación del sistema de alimentación de la balsa, que sin duda debió ser aéreo, aunque llama la atención la presencia de un molino perforado de calcarenita fosilífera integrado en el eje de M-24, el cual podría haber servido como encaje del surtidor de la piscina, procedente de las fistulae del apodyterium.

\section{La sala fría (¿unctorium?)}

El apodyterium/frigidarium, que acabamos de describir, mantiene comunicación con dos salas: el ambiente 2 (al sur), a través del cual se abre paso por un umbral de $95 \mathrm{~cm}$ situado en el extremo suroeste, y el ambiente 6 (al oeste). En lo que respecta al primero de los espacios citados, el vano descrito permite acceder a una despejada sala prácticamente cuadrada de $36 \mathrm{~m}^{2}$, que se encuentra totalmente pavimentada por un suelo hidráulico de opus signinum de unos $10 \mathrm{~cm}$ de espesor, el cual está rematado por una protección perimetral a modo de reborde engrosado de media caña de unos 30 $\mathrm{cm}$ realizado con el mismo material, una característica habitual en salas en las que es frecuente la presencia de agua (Fig. 6). La falta de evidencias funcionales sobre la actividad desarrollada en este espacio solo nos permite confirmar que se trata de una sala que no dispone de elementos calefactantes ni en el suelo ni en las paredes, y que presenta conexión directa únicamente con el apodyterium en retrógrado ya que, aunque el caldarium se desarrolla a su lado (ambiente 1), la presencia de ladrillos de las concamerationes de la sala calefactada en el muro divisorio entre ambos espacios impide defender la presencia de un vano de comunicación entre ellos. Esta sala cabría ser interpretada como parte de algunos de los servicios complementarios como unctoria o destrictaria relacionados con la realización de masajes o aplicaciones de aceites habituales en estos equipamientos, así como con la limpieza del cuerpo tras la realización de prácticas deportivas, en este caso menos probable por ausencia de palestra tanto aquí como en la mayoría de edificios termales castrenses (Nielsen 1993: 79). En relación con un posible uso de esta sala como frigidarium, somos conscientes que no siempre es necesaria la presencia de bañeras de mampostería, pudiendo encontrarse presentes contenedores de madera, bronce o incluso plomo destinados al baño frío individual (Reis 2004: 37), los cuales raramente dejan testimonio arqueológico de su presencia. Sin embargo, partiendo del hecho de que ya existe un apodyterium/ frigidarium que dispone de una piscina fría en estos baños, debemos relacionar definitivamente esta sala
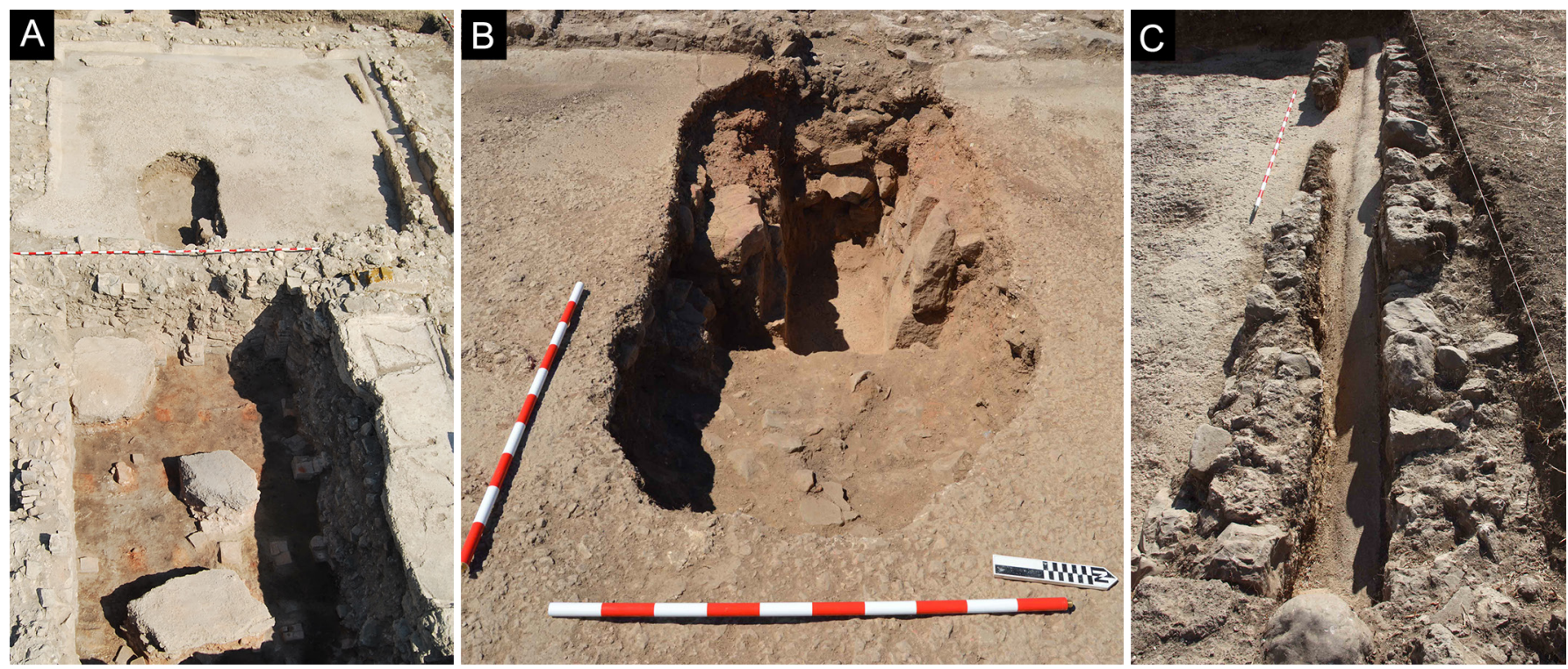

Figura 6. Sala fría (ambiente 2). Vista general desde el oeste (A); detalle del horno H-I que rompe la pavimentación de la sala (B) y vista de la canalización perimetral que reutiliza la sala (C). 
con los otros usos ya referidos, en consonancia con la ampliación de espacios de ocio que experimentan los edificios termales erigidos a partir de la segunda centuria (Gros y Torelli 1994: 231), como el caso que nos ocupa, que requieren de mayores espacios ajenos a los baños, destinados a estas otras actividades en las que podríamos incluir principalmente las ya citadas, si bien debemos recordar que en estos ambientes no solo tienen lugar actividades higiénicas sino que, como indica Maréchal (2012: 152), se llevan a cabo también prácticas profesionales o económicas (como actividades medicinales, venta de comida, servicios de prostitución), o de esparcimiento personal (juegos, prácticas religiosas, etc.), todas ellas compatibles con las características de la estancia a la que nos referimos.

Lo que sí tenemos claro es que a partir de la gran fase de reformas acaecidas en torno a inicios del IV d. C. esta sala cesa su actividad para destinarse a espacios de servicio. La evidencia principal queda constatada a través de la apertura de un praefurnium que complementará la alimentación de calor del caldarium, que se crea perforando el suelo de la sala y abriendo una apertura subterránea que conectaba el hypocaustum de la sala calefactada con esta nueva estructura de combustión (H-I). Este horno (Fig. 6B) quedará definido únicamente por un corto pasillo sustentado lateralmente en adobes rubefactados y un pequeño espacio trasero sin rematar, a través del cual descender a la zona de combustión. El resto de reformas que afectan a esta sala quedan materializadas en la apertura de un nuevo vano de conexión con el apodyterium, en este caso situado en el extremo oriental del muro divisorio, pero especialmente se ven reflejadas en la inserción de un pequeño murete de pobre factura y apenas $20 \mathrm{~cm}$ de espesor, realizado con arcilla y mampuestos de tamaño y calidad variable dispuestos sobre el suelo de opus signinum, corriendo en paralelo a los muros oriental y meridional por el interior de la sala, generando así una especie de canal de unos $30 \mathrm{~cm}$ de anchura que parece estar diseñado para reconducir algún líquido desde la esquina noroeste hasta algún punto del extremo oriental, siguiendo la pendiente descendente del propio canal y de la sala (Fig. 6C). Si recordamos que tanto el alveus como la entrada de agua del posible acueducto externo está en el extremo suroeste del edificio, es posible que este canal sirviese para reconducir estas aguas que vertían a las canalizaciones exteriores orientales, rodeando la habitación internamente por su perímetro. Desconocemos la fi- nalidad real que tuvo, ya que no disponemos de evidencias arqueológicas que nos informen sobre ello, si bien esa efímera construcción serviría para dar salida a las aguas sobrantes que suministraba este conducto.

\section{El circuito de salas calefactadas: tepidarium y caldarium}

Desde el distribuidor que representa el apodyterium/ frigidarium se accede también al circuito de salas calefactadas que comienza con el ambiente 6. No disponemos de evidencias de este vano por encontrarse los muros conservados por debajo del nivel de uso, si bien existen testimonios indirectos de su presencia, ya que en esta zona el muro que divide ambas salas (M-9) se estrecha en $25 \mathrm{~cm}$ y el pavimento del apodyterium se extiende unos $30 \mathrm{~cm}$ más que en el resto de este perfil. Esta estancia, a la que se accedería a través del citado acceso, es la primera de las salas calefactadas del circuito, como evidencian los restos de pilae de su hypocaustum,
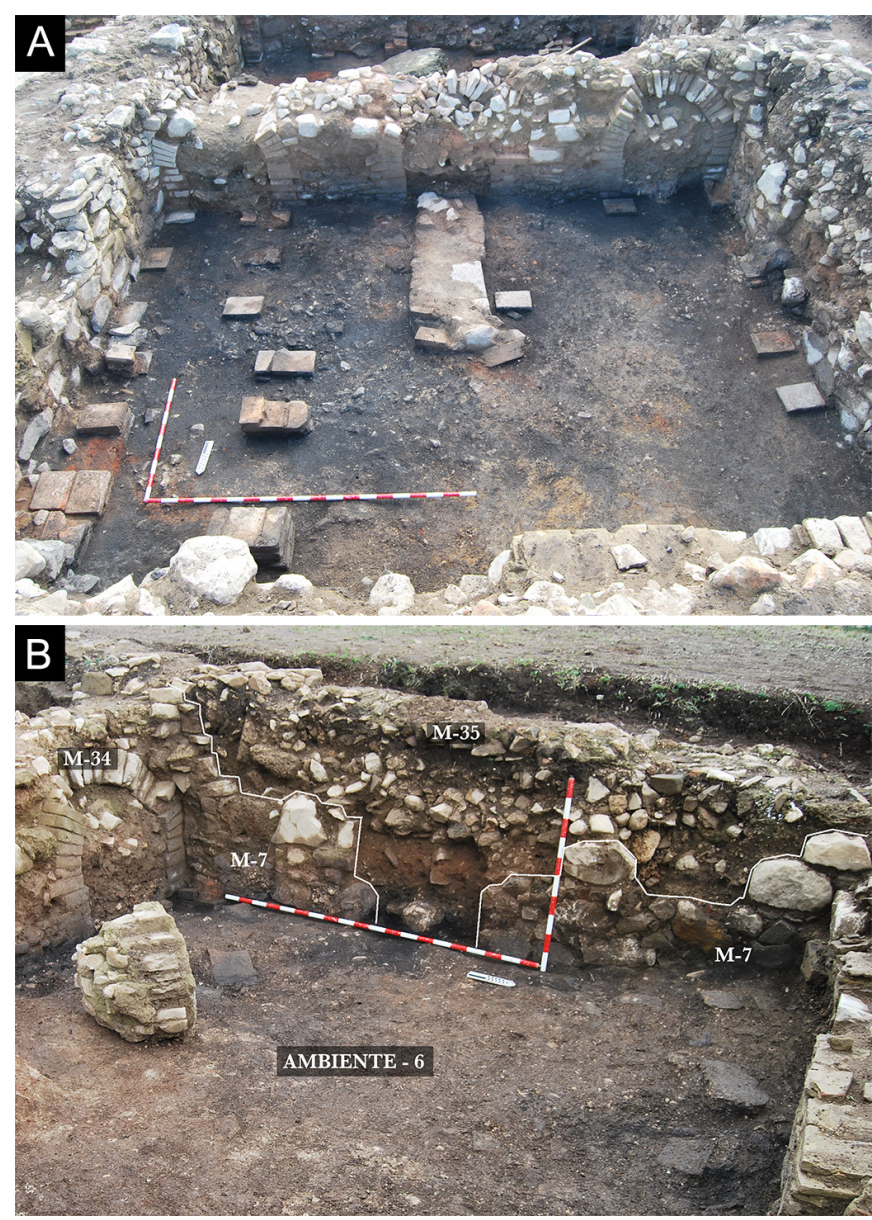

Figura 7. Tepidarium. Vista general (A) y detalle de la rotura del muro occidental (M-7) para la inserción del praefurnium (B). 
por lo que se correspondería con el tepidarium (Fig. 7). Se define como una sala rectangular de $5,20 \times 3,65 \mathrm{~m}$, que está completamente calefactada pero que no muestra evidencias de otros elementos estructurales singulares pertenecientes a su primera fase salvo las citadas pilae conservadas y las huellas de las faltantes, que atienden a la misma cadencia observada en el contiguo caldarium. Dado que no hemos recuperado en este ambiente evidencias de las concamerationes y otros elementos del sistema de calefacción parietal, remitimos a las descripciones aportadas al referirnos al caldarium, donde estos testimonios son más ilustrativos.

Este tepidarium originariamente estaba alimentado únicamente por el horno principal, situado en el vértice suroeste del edificio, siguiendo un esquema lineal coherente con este tipo de edificios (Fig. 3). Sin embargo, entre las reformas atestiguadas en el balneum observamos la adición de un nuevo horno que alimentaría directamente esta sala templada, y que se situó en el eje de su cierre occidental, implicando la modificación en espesor de M-7 y la inserción de un nuevo muro (M-35), notablemente más estrecho que el anterior, que incluía la apertura de la embocadura del nuevo praefurnium (Fig. 7B). Otras modificaciones estructurales fruto de estas reformas han dejado igualmente testigo en esta estancia, como son la inserción de un gran pilar en el eje de la hipocausis (M-36), posiblemente fruto de la reparación destinada a suplir la falta de consistencia de algunas suspensurae, y la modificación de la cadencia de pilae en el extremo noreste de la hipocausis, que sin duda responde a idénticos fines.

El recorrido natural del circuito balneario permite la conexión del tepidarium y el caldarium a través de un acceso que debió existir en el muro M-34, y del cual no tenemos evidencias físicas, posiblemente porque el nivel de conservación actual se encuentra justo por debajo de la altura a la que se emplazaría este vano de acceso. Atendiendo a esta reflexión, estimamos que la puerta se debió situar por encima de $1,10 \mathrm{~m}$ con respecto a la base del hypocaustum. En lo que respecta a posibles paralelos, observamos que el pequeño balneum situado en el interior del castellum de Tamuda presenta una estructuración similar, apreciándose en este caso las huellas del acceso que intercomunica ambas salas calefactadas sobre el arco central de los tres presentes, y que podríamos utilizar como referencia (Campos et al. 2012: fig. 4), ya que en este muro divisorio que analizamos, bajo este nivel de utilización también se han conservado tres amplias arcadas realizadas con
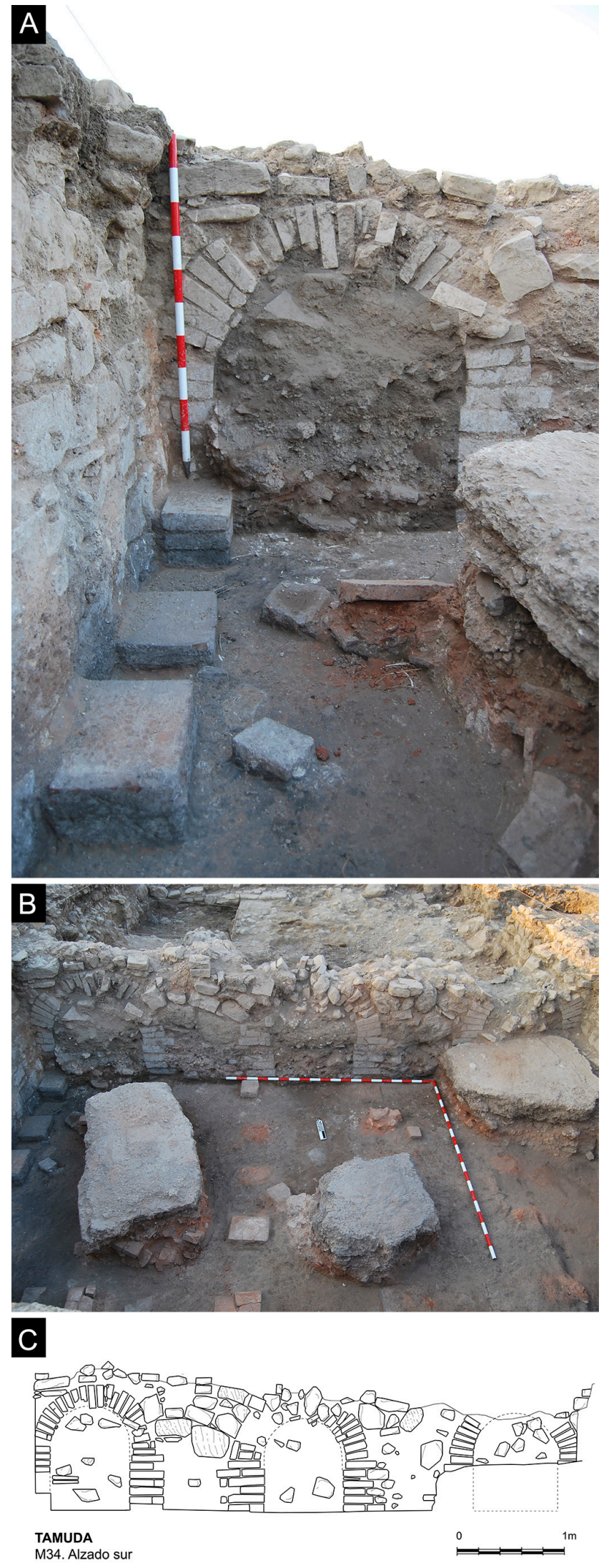

Figura 8. Muro divisorio de las salas calefactadas (M-34). Detalle del arco oriental del muro con detalle de las pilae del caldarium en primer plano (A). Fotografía (B) y dibujo (C) del alzado sur. 
material latericio que permiten la intercomunicación inferior de las dos salas calefactadas para facilitar el trasvase calorífico, como es habitual en este tipo de equipamientos, siguiendo la cadencia propia de las líneas de pilae (Fig. 8).

El caldarium al que hemos hecho alusión, se sitúa inmediatamente al sur del tepidarium, y presenta su misma anchura con una longitud mayor al disponer del alveus al sur de la sala, sumando unas medidas interiores totales de 5,2 $\times 4,45 \mathrm{~m}$, aunque si restamos el espacio ocupado por la bañera y las concamerationes obtendríamos un espacio interno aprovechable de 15 $\mathrm{m}^{2}$ (Figs. 3 y $8 \mathrm{~B}$ ). En lo que respecta a la citada bañera, esta se dispone apoyando su cara más amplia en la pared en la que se inserta el praefurnium del horno principal, que correría bajo la misma, de manera que pudiera calentar la bañera por contacto directo, aunque lo más probable es que dispusiese además de una caldera sobre el horno que permitiera su alimentación directa. Podemos observar que el alveus estaba revestido internamente de opus signinum y disponía, al menos, de un escalón en su extremo corto (oriental) (M10), como en el caso de las termas urbanas de Baelo Claudia, si bien es probable que los otros dos muretes más distales existentes en ambos extremos de la bañera estuviesen igualmente abancados (M-11 y M-8), sumando de esta manera unas dimensiones totales de $5,20 \times 1,35 \mathrm{~m}$ atendiendo a las medidas mínimas conservadas; aunque debemos apuntar que no se ha conservado su cara septentrional, por lo que no podemos descartar que dispusiese de una anchura algo mayor. A nivel de volumetría interior, podemos apuntar que el alzado meridional del alveus se ha conservado con una altura de $60 \mathrm{~cm}$ que debemos tomar como referencia mínima para cualquier reconstrucción en este sentido.

Los aspectos de mayor complejidad técnica y singularidad arquitectónica de las dos salas calefactadas son los sistemas de circulación del calor (suspensurae y concamerationes), sistemas que han podido ser bien analizados para el caso que nos ocupa.

En lo que respecta al hypocaustum, gracias a los testimonios conservados in situ podemos confirmar que está formado por una retícula de pilae de ladrillos rectangulares que en su parte superior forman arcadas que se abren en dirección este-oeste, formando así tirantes que discurren en esta misma orientación sustentados en cinco de estas arcadas. Hemos podido reconstruir tanto la disposición de los arcos como su
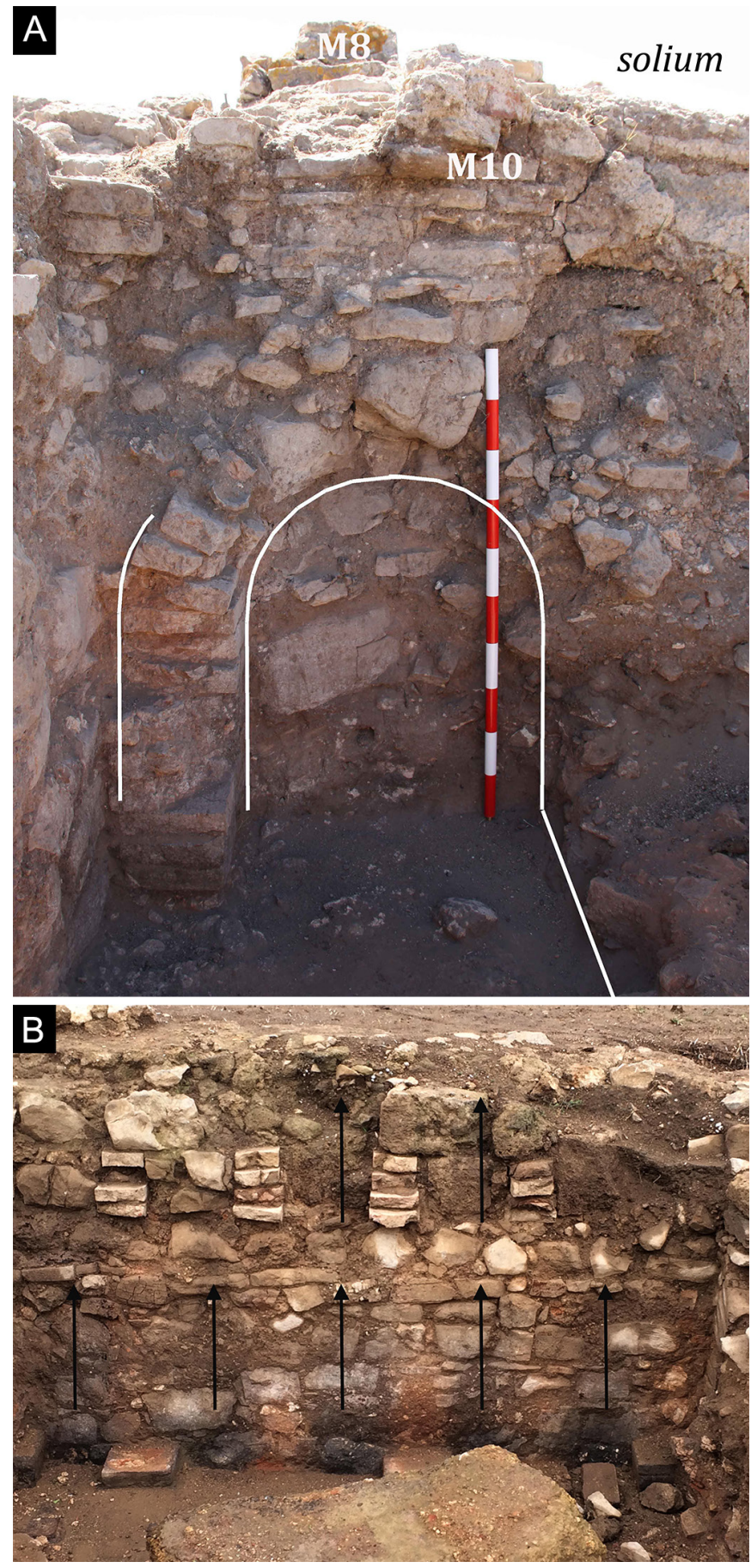

Figura 9. Caldarium. Reconstrucción del arco de las pilae en base a los testimonios conservados in situ en el vértice sureste de la sala (A) y detalle del perfil occidental de la sala donde se aprecian las huellas del humo sobre la pared, evidenciando el tiro entre los pilares (B).

altura a partir de los testimonios conservados en las pilae del vértice sureste (Fig. 9A) y la comparación con los arcos existentes bajo M-34, que comparten la misma arquitectura y cadencia que los situados en los extremos y en el eje de la sala. A estos datos debemos 
sumar la información complementaria ofrecida por las huellas del humo impregnado en la pared occidental del caldarium que confirmaban la correcta localización del tiro entre las correas de arcos y la continuidad del tránsito del aire a través de las concamerationes, al observarse que discurrían siguiendo los huecos situados entre los ladrillos de sustentación superiores (Fig. 9B). Esta reconstrucción nos permite confirmar que el tepidarium disponía de 6 correas de arcos y el caldarium de otras tantas, sin contar la sustentación de la bañera (no excavada). También hemos podido corroborar que las arcadas de pilae se alzarían en altura en torno a $1 \mathrm{~m}$, situándose sobre ellas la pavimentación. A este respecto, debemos apuntar que hemos podido localizar varios bloques del pavimento original desplomados en el interior del caldarium, por lo que igualmente podemos afirmar que la sala estuvo cubierta de un grueso piso de opus signinum de 15 $\mathrm{cm}$ de espesor medio (Fig. 8B), el cual se asentaría sobre una superficie latericia de la cual no hemos obtenido testimonios in situ pero que serviría de asiento del conglomerado de opus signinum, como puede observarse en otros paralelos análogos como los de los baños de Thamusida (Rebuffat et al. 1970: pl. XVII).

En lo que atañe al sistema de distribución de calor parietal, debemos apuntar que se corresponde con una técnica bien conocida en el Estrecho de Gibraltar y con paralelos bien constatados en la provincia Tingitana en conjunción con los sistemas de cubrición documentados, especialmente en ámbitos cercanos como en las Thermes du Fleuve, en Thamusida (Ma- rruecos), que conservan como en nuestro caso parte del sistema de concamerationes in situ (Camporeale 2008: 128 y 136-137; Rebuffat et al. 1970; Lancaster 2015b: fig. 5), o los afines acabados de las gaditanas termas de Carteia (Roldán y Bustamante 2016: fig. $10 \mathrm{~b})$. Este sistema es claramente definible para nuestro balneum gracias a los testimonios preservados en las paredes oriental y occidental del caldarium, y a las piezas recuperadas durante la excavación, pero en especial a la identificación de las placas embutidas a uno y otro extremo del alveus, donde se preservaron in situ (Figs. 10A-C). Este sistema de sujeción de la cámara de aire parietal estaba formado en nuestro caso por series de pilas de 4 ladrillos con muesca, también conocidos como ladrillos "de camiseta", que sobresalen del perfil vertical de las paredes hacia el interior de la sala en 9,5 cm. Estas columnas de ladrillos miden $25 \mathrm{~cm}$ de altura en conjunto y se separan entre sí unas de otras lateralmente $34 \mathrm{~cm}$ y verticalmente $40 \mathrm{~cm}$, cubriendo con esta cadencia al menos las paredes interiores oriental y occidental. Por encima de las pilas de ladrillos se dispondrían los ladrillos en forma de "H", o ranurados, colocados verticalmente de manera que coincidiesen los surcos presentes en ambos y prolongasen el canal a través del cual se deslizarían las placas cerámicas de pared que creaban las concamerationes, tal y como se pueden advertir en las propuestas reconstructivas (Fig. 10D). Hemos observado que la primera pila de ladrillos "de camiseta" (inferior) presentaba el tercer ejemplar sin muescas, posiblemente para servir como base sobre la que asen-
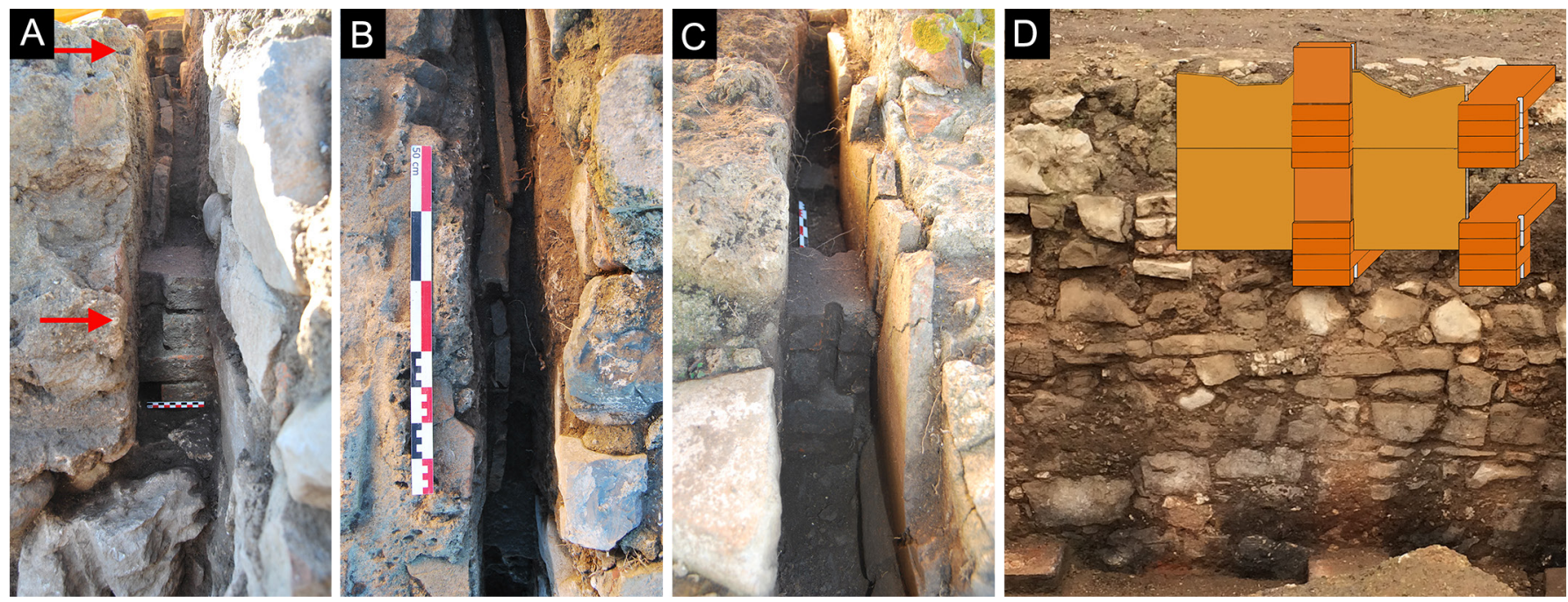

Figura 10. Detalle de las concamerationes preservadas in situ a los lados del alveus (A-C), y propuesta reconstructiva parietal de las concamerationes recreada sobre la pared occidental del caldarium (B). 


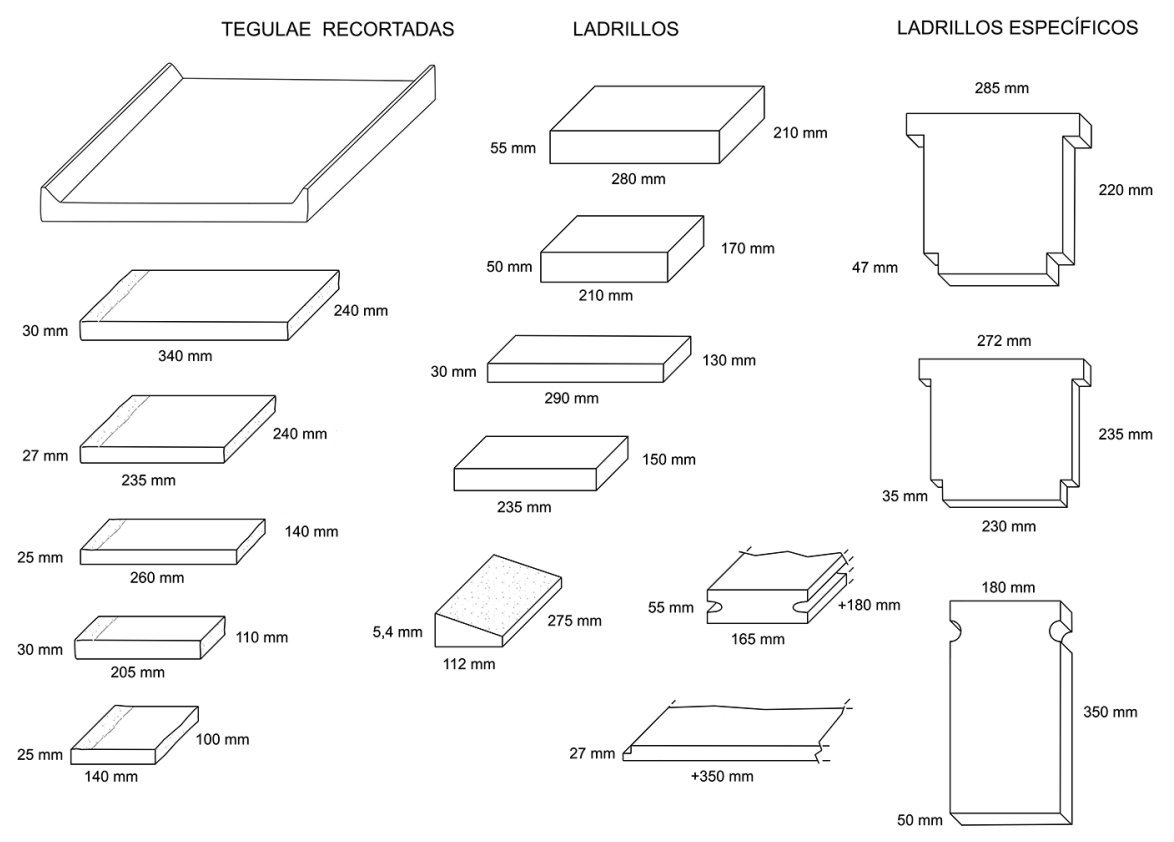

Figura 11. Tipología de los ladrillos recuperados entre los contextos del balneum, con indicación de medidas generales.

tar la primera hilada de placas verticales. En lo que respecta a estas placas introducidas verticalmente en estos encajes, los testimonios conservados in situ nos muestran que normalmente eran placas planas con bisel lateral o lengüeta, para favorecer este deslizamiento y encaje, si bien hemos observado que era habitual que fueran sustituidas por planchas de tegulae recicladas a las que habrían recortado las pestañas laterales, en una muestra más de la amplia reutilización de material latericio atestiguada en este balneum (Fig. 11).

Atendiendo a esta técnica, fueron generadas las cámaras de aire parietales, pero en el yacimiento, además de los materiales latericios de las concamerationes y las suspensurae, se han documentado evidencias del sistema de cubrición, que podemos adscribir al tipo de cubiertas con nervadura "armchair voussoirs" analizadas in extenso por Lancaster (2015a; 2015b), que implican el uso de ladrillos cuadrangulares con apéndices y rebajes distales (Figs. 11 y 12A), también conocidos como ladrillos con escotadura, "armchair", o costilla de dovela, adscribibles dentro del Grupo 3a de Bouet (1999: fig. 54), los cuales eran usados para crear los nervios de bóvedas con doble cámara en algunos tipos de edificios termales de la Galia, Hispania y la Tingitana, y que están bien constatadas en conjunción con el sistema parietal descrito por nosotros especial- mente en la Tingitana y el Estrecho, como ya hemos citado con anterioridad (Camporeale 2008; Roldán y Bustamante 2016: fig. $10 \mathrm{~b})$, pero con acabado diferenciado del usado para el balneum situado intra moenia (Campos et al. 2012: fig. 3). En referencia a la documentación de estas piezas latericias, debemos apuntar que hemos recuperado varios ejemplares situados entre los niveles de abandono inicial del balneum. La función original de este tipo de cubierta era aligerar la techumbre de peso y crear una cámara para evitar la humedad, siendo un desarrollo posterior su uso para la calefacción de la sala al incorporar la doble escotadura y crear una doble cubierta. Este sistema de cubierta se asoció a techos de madera y estructuras balnearias con cierta difusión en ámbito villático (Lancaster 2015b: 465), aunque si atendemos al caso de las termas de Thamusida y Tamuda, no podemos descartar que exista también cierta relación con la presencia de asentamientos campamentales en este ámbito geográfico (Rebuffat et al. 1970: fig, 18) (Fig. 12).
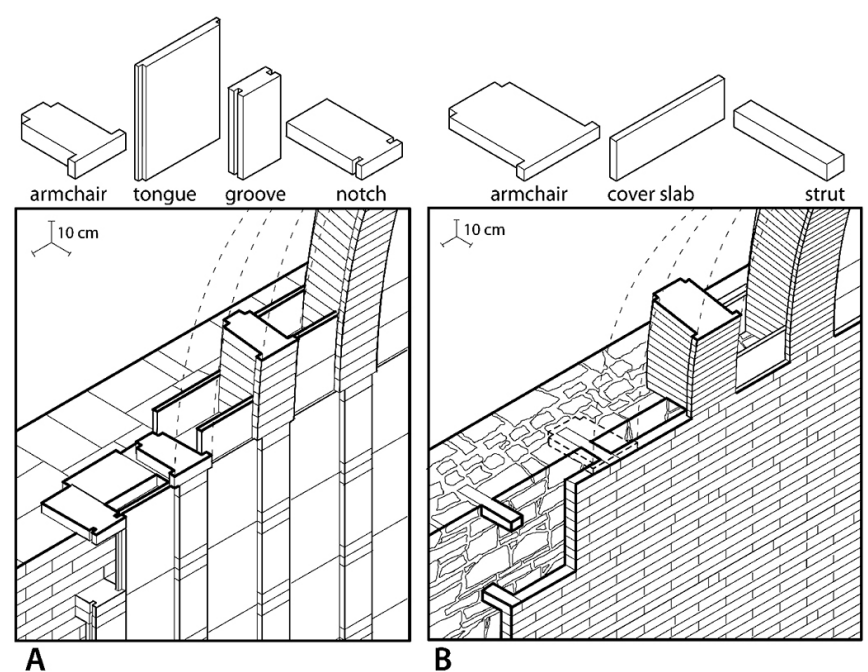

Figura 12. Propuesta reconstructiva realizada por Lancaster para los recubrimientos parietales y cubiertas del tipo "armchair voussoirs" (Lancaster 2015a, 2015b: fig. 5) de las variantes utilizadas en el balneum del barrio oriental de Tamuda (A) y en el pequeño balneum situado dentro del castellum (B). 


\section{La generación del calor: Los propnigea}

En lo que respecta a la generación del calor para estas salas, la configuración edilicia original no deja dudas de la presencia de un horno principal, situado al sur del caldarium, siguiendo un eje longitudinal y ofreciendo una alimentación directa por debajo del alveus (Fig. 13). El horno de este propnigeum no ha sido completamente excavado, quedando pendiente la documentación de su cierre meridional, si bien se identifican claramente dos muros de cierre lateral de gran espesor $(1,4 \mathrm{~m})$, mientras el muro norte, donde se sitúa el praefurnium, disponía de un ancho afín al resto de los ejes maestros del edificio. Debemos destacar en su lateral occidental la presencia de una pavimentación de entrada vinculada al acceso a esta sala, coincidente con el nivel de uso del edificio. En lo que respecta al praefurnium de la sala de combustión, responde a la definición del tipo 6 de Reis (2004: fig. 9), tomado de la clasificación de Degbomont (1984), que lo identifica dentro del tipo "de caño externo con aletas", ya que esta embocadura se abre al horno, protegida lateralmente por dos muros realizados con arcilla rubefactada y piedras, a semejanza de ejemplos hispanos como el de Can Sans, y atendiendo a una alimentación lineal caldarium-alveus-praefurnium observada en ejemplos hispanos como el de El Moro (García-Entero 2005: figs. 225 y 232). El praefurnium se desarrolla por debajo del muro norte, conectando con el caldarium a través de un arco de ladrillos parcialmente conservado, que se abre en primer lugar bajo la bañera de la sala calefactada, ofreciendo una irradiación directa por contacto a este alveus, para extenderse en primer lugar por el caldarium y continuar al tepidarium a través de los arcos inferiores del muro divisorio de ambas salas (M-34). No

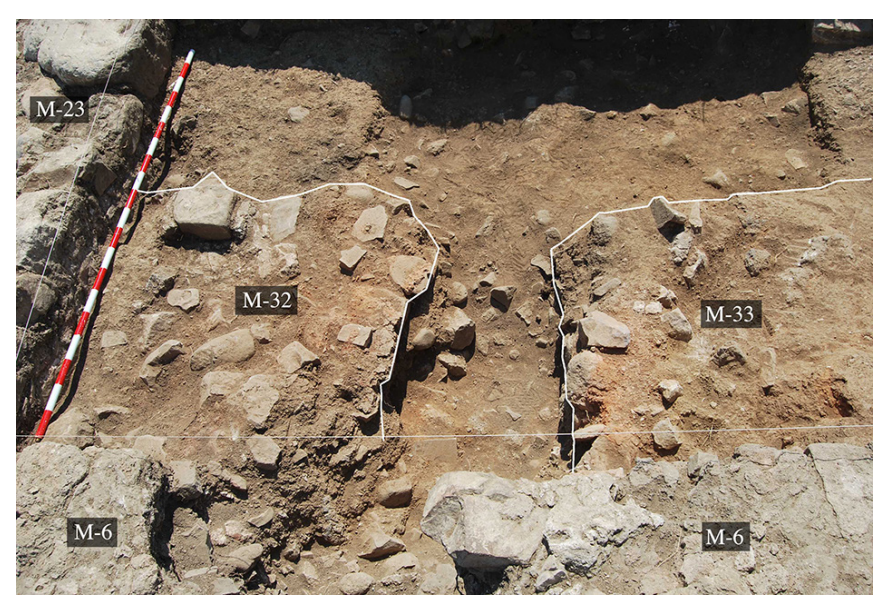

Figura 13. Foto general del horno principal del balneum. conservamos evidencias de las calderas de bronce que deberían situarse sobre el horno, si bien es muy poco habitual encontrar testimonios de este tipo de recipientes, que deberían suministrar el agua caliente para alimentar la bañera contigua.

Esta configuración original lineal fue alterada en dos ocasiones, al añadirse los dos nuevos praefurnia ya referidos. El primero de ellos se instaló para alimentar el tepidarium, y dotarle así de mayor potencia calorífica. La instalación de este horno supuso la remodelación de la pared de cierre occidental, que en este tramo perdió volumen e incluyó una irregular apertura para la embocadura del praefurnium (Figura 7B). El segundo de estos se realizó abriendo una embocadura igualmente irregular en el muro este del caldarium y excavándose en el pavimento interior de la sala contigua, quedando la misma como sala de servicio a partir de ese momento (Figura 6B). Este horno, que sí ha sido excavado íntegramente a diferencia de ejemplo anterior, podríamos englobarlo en el tipo 5 o "de caño externo", atendiendo a la misma tipología referida con anterioridad (Reis 2004: fig. 9), al usar un pasillo con adobes rubefactados, y estaría destinado a reforzar la alimentación de calor del caldarium desde el este, si bien desconocemos si respondería a un deseo de complementar al calor generado por el praefurnium principal, o se habría construido para sustituirlo.

\section{Las latrinae y otros espacios de servicio comple- mentarios}

El resto de espacios de servicio del edificio termal se caracteriza por la presencia de una sala alargada situada al sur del ambiente 2, y sin conexión directa aparente con el mismo (ambiente 4), que estaba parcialmente pavimentada con opus signinum y que presentaba un recipiente cerámico circular integrado en este suelo (Fig. 14), totalmente colmatado con cal, cuya funcionalidad precisa se desconoce. En su entorno se pudieron identificar amplios niveles de ceniza que se pueden relacionar con los contiguos hornos pero que no podemos descartar que se relacionasen con funciones accesorias de calentamiento de productos que se llevarían a cabo en este sector (limpieza de instrumentos, cocinado de productos, etc.).

Uno de los equipamientos usualmente relacionados con los balnea son las latrinae, especialmente en ambientes campamentales como el que nos ocupa. A este respecto, debemos apuntar que no hemos podido confirmar fidedignamente su ubicación exacta, si bien 


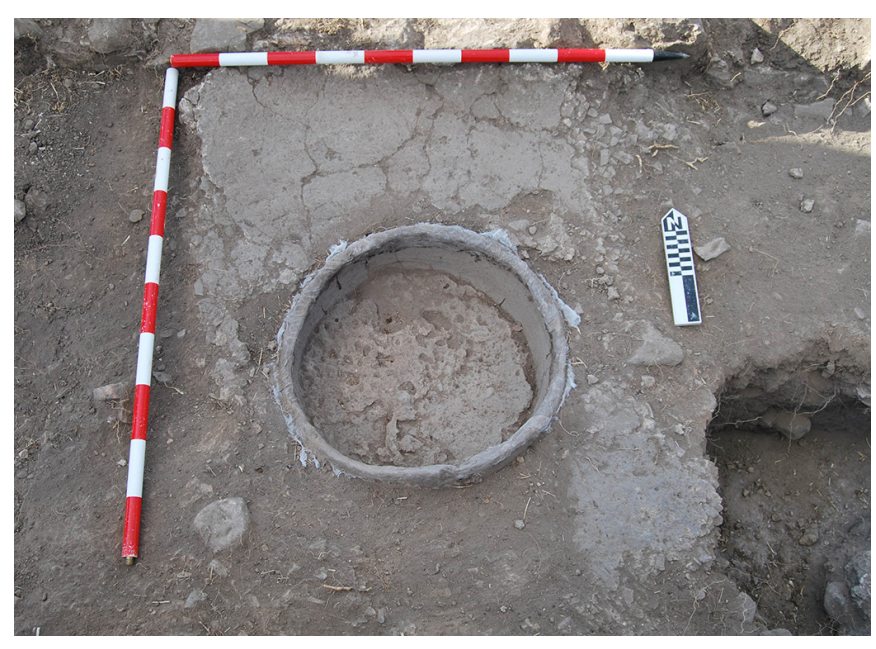

Figura 14. Detalle del recipiente cerámico embutido en el pavimento de la sala de servicio meridional (ambiente 4).

disponemos de evidencias suficientes para plantear su localización inicial al exterior del sector oriental del edificio. En este sentido debemos apuntar que no es anómalo que respondan a instalaciones de menor calidad estructural adosadas al edificio principal, lo que justificaría la ausencia de documentación dentro de los límites del edificio balneario. Atendiendo a contextos similares, observamos que es habitual que las letrinas se encuentren separadas del eje de salas calefactadas y próximas o anexas al apodyterium, donde desaguan las piscinas, para reciclar sus aguas como empuje de los residuos, características que comparten los edificios balnearios presentes en campamentos militares como el de Brocolitia (Carrawbrugh), Cilurnum (Chester) o Vindolanda (Chesterholm) (Nielsen 1993: vol. 2, 135 y 50). Atendiendo a esta lógica, en nuestro caso observamos que el agua de la piscina principal discurre de oeste a este atravesando el apodyterium mediante un desagüe cubierto de losas de piedra (Figs. 4B y 4C) hasta salir de los límites del edificio por el extremo oriental en el punto donde confluye con otra suave canaleta recubierta de opus signinum que circula adosada al exterior del citado paramento (Figs. 15A-C), para dirigirse unidas en un mismo desagüe hacia el este. En este extremo del edificio observamos que, además de la citada canalización abierta, que parte de un alimentador situado en un muro situado varios metros más al sur, está presente una amplia pavimentación de opus signinum de calidad variable (Fig. 3). Estos amplios espacios pavimentados y asociados a canaletas y desagües, bien documentados al noreste y al este del edificio, que estarían abiertos o porticados, podrían vincularse directa o indirectamente a la actividad de las latrinae. Es muy ilustrativo a estos efectos el paralelo de las Termas I de Labitolosa, que muestran una canaleta similar sin cubierta, que circunda el edificio por el norte y que los autores han asociado con la presencia de las letrinas y como desagüe de
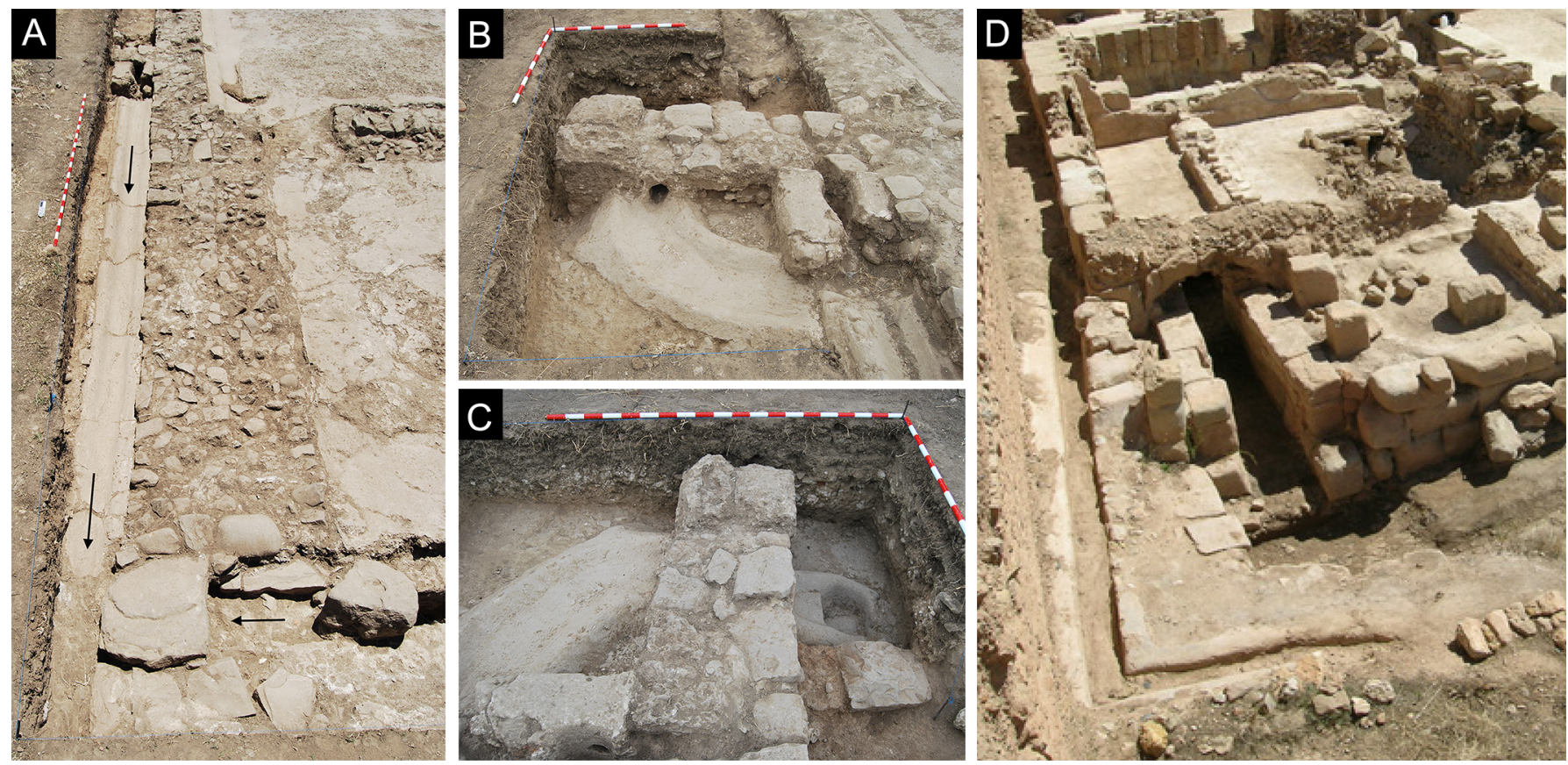

Figura 15. Canaleta oriental exterior. Vista general (A) y de detalle del extremo meridional (B y C); paralelo de la canalización que rodea las Termas I de Labitolosa por el oeste (D) (Asensio et al. 2016: 95). 
los baños y las aguas pluviales de la techumbre (Asensio et al. 2016: 95 y 118) (Fig. 15D). Como soporte a este planteamiento debemos recordar que este extremo del edificio es el más distante del campamento y el más próximo al contiguo arroyo situado inmediatamente al este, el Uad Sequin o Tamuda, cuyo nacimiento constituiría un recurso hídrico a la vez que su cauce bajo serviría como un punto de desagüe para los residuos.

\section{Fases constructivas del balneum}

Los espacios descritos con anterioridad han sido objeto de una evolución arquitectónica que ha conllevado el surgimiento de nuevos equipamientos y la supresión de otros, en ocasiones generando importantes cambios en el propio concepto del baño, que se adaptan a la realidad de los usos otorgados a este equipamiento para cada momento. No resulta sencillo en ocasiones, debido al solapamiento arquitectónico, identificar una secuencia lineal en estos procesos, si bien en este apartado procederemos a presentar la propuesta de fases constructivas que identificamos en el edificio balneario.

Al inicio de este trabajo ya enumeramos los testimonios datacionales más significativos que nos permiten defender la construcción de los baños bajo el gobierno de Adriano. Es en este momento cuando se llevaría a cabo el levantamiento volumétrico del edificio, erigiéndose completamente con la extensión definitiva documentada. Los espacios más claramente definidos para esta primera fase son la presencia de un apodyterium/frigidarium, una secuencia de dos salas calefactadas (tepidarium y caldarium) alimentadas por un horno ubicado al sur de ambos ambientes caldeados, y la existencia de una última sala situada al sureste, que funcionaría a modo de unctorium o con usos similares. A nivel de detalle, hemos documentado que al inicio de esta primera fase el apodyterium/frigidarium dispondría de un pediluvium o lavapiés junto al acceso principal, que sería rápidamente sellado para que no obstaculizara el paso hacia la piscina situada en el vértice noroccidental, no pudiendo descartar que inicialmente existiera solo el pediluvium y la piscina fría fuese una innovación posterior situada dentro de esta misma fase, si bien la homogeneidad constructiva del edificio y la presencia de gruesos muros iniciales que delimitan el espacio de baño nos invitan a decantarnos por la coexistencia de ambas balsas en los primeros momentos. En esta fase, el apodyterium/frigidarium dispondría ya de los bancos perimetrales, las conducciones de sumi- nistro hídrico y el surtidor, que no parecen representar alteraciones al diseño original, al igual que la ya mencionada piscina fría, que inicialmente dispondría de un acceso escalonado que cubriría toda su anchura. Sí presentaría una visión diferenciada el canal de desagüe que discurre bajo el suelo de esta sala de oeste a este, el cual dispondría de una cubierta distinta, posiblemente menos abrupta, ya que la tapa documentada in situ durante la excavación pertenece a una reforma más tardía. Con respecto al resto de espacios documentados, el apodyterium conectaría con el unctorium por un único acceso de entrada y salida, al igual que con el tepidarium, a partir del cual se accedería al caldarium en un recorrido coherente en el que estaría presente el alveus situado al final del recorrido calefactado. Esta primera fase también contemplaría la presencia de unas posibles latrinae al exterior del edificio, equipamiento que no se vería modificado en esencia a lo largo de la vida útil del edificio, así como una zona de servicio meridional.

La fase de reformas principales se llevaría a cabo a finales del s. III o inicios del IV d. C., quedando bien atestiguada a nivel datacional por la modificación de la cubierta del canal de desagüe que discurre bajo el apodyterium/frigidarium. Existen otras reformas que no han podido ser datadas de forma tan clara pero que modifican significativamente la estructuración inicial, por lo que creemos que responderían a esta misma fase de amplias remodelaciones, como la inserción de nuevos hornos al oeste del tepidarium (ambiente 6) y al este del caldarium (ambiente 1), obligando este último a modificar los usos de la sala contigua, que dejaría de funcionar como un unctorium para servir únicamente como sala de servicio. Esta sala accesoria dispondría ahora de dos accesos y de una canalización perimetral posiblemente como adaptación a otras conducciones hídricas que habrían quedado en desuso. Asociadas a esta fase de reformas, o tal vez a fases intermedias de remodelaciones o reparaciones parciales, deberíamos sumar pequeñas obras como la documentada en la piscina fría, que pasaría a incluir un banco en el lateral meridional; la documentada en el apodyterium/ frigidarium, consistente en la adición de varias repavimentaciones en el este de la sala; o la atestiguada en la hipocausis del tepidarium, que remodelaría las pilae del vértice noreste e incluiría un gran pilar central de sustentación para evitar el desplome del suelo. Todas estas pequeñas transformaciones no han dejado evidencia datacional, pero responden a una lógica actividad 
de mantenimiento propia de un edificio que está en uso durante varias centurias. La consecuencia de la suma de estas modificaciones y remodelaciones observadas será la configuración de un edificio más sencillo y mejor calefactado, que prolongaría su vida útil hasta la primera mitad del s. V d. C. cuando se abandonaría definitivamente el campamento y los baños.

\section{El suministro hídrico al balneum oriental}

En lo que respecta al suministro del edificio termal para dar servicio a sus piscinas y bañeras, este se llevaría a cabo a través de las conducciones existentes al oeste del balneum las cuales, procedentes del norte, se bifurcan al acercarse al balneum; dirigiéndose una al edificio balneario para adentrarse en él por la zona en la que se sitúa el alveus, mientras la otra se dirige a un depósito abierto situado inmediatamente al suroeste del edificio, el cual también podría actuar como reservorio auxiliar y para el suministro hídrico destinado a otros fines, como evidencia el canal que, partiendo de su rebosadero, se abre al oeste (Fig. 3B). Esta conducción y la citada pileta, ya constatadas parcialmente por Pelayo Quintero en 1944 (Quintero y Giménez 1945: 10 y 11), podrían responder a una derivación del acueducto campamental, posiblemente asociado al nacimiento del citado arroyo Tamuda. Este, aunque de corto recorrido, pero procedente de las altas cotas del Gorgues (el macizo de ambiente kárstico situado al sur de Tetuán), podría suministrar agua potable al asentamiento a través de un acueducto que accedería al castellum y al vicus militar desde el sur, como sugiere ya Pelayo Quintero en los años 40, al documentar la presencia de posibles conducciones y dos depósitos hídricos situados en la ladera de este macizo en el camino hacia Tamuda (Quintero 1941: lám. 1). En este sentido, César Morán ya defiende que el citado acueducto se adentraría en el fuerte directamente por el sur y, tras satisfacer las necesidades de agua del destacamento, saldría del fuerte para conducirse a los recipientes hídricos situados en este barrio oriental y cubrir otras necesidades secundarias (Morán y Giménez 1948: 26), que ahora sabemos que en buena parte se podrían tratar del aprovisionamiento hídrico al balneum oriental. Aunque los recientes estudios planteados para el ciclo del agua en el castellum de Tamuda cuestionan el uso del citado acueducto a partir del s. II d. C. y centran sus planteamientos de suministros en la captación del agua de lluvia (Bermejo et al. 2015: 135136), lo cierto es que las necesidades emanadas en ese mismo momento de la construcción de este balneum, dotado de piscina y bañera, implican la presencia de un suministro hídrico constante y abundante para el castellum y sus cannabae, abriendo nuevas perspectivas de análisis a este respecto que obligan a replantear estos presupuestos.

\section{Disfrutando del baño. Planteamiento y reconfiguraciones en los circuitos de uso del balneum oriental de Tamuda}

La arquitectura termal del balneum que analizamos resulta difícil de encajar dentro de los circuitos de uso definidos a partir de las tipologías edilicias al uso (Krencker et al. 1929: 234-240), una opinión compartida a nivel general por otros autores que aluden a la dificultad de encasillar buena parte de los balnea atendiendo a la amplia variabilidad tipológica existente (Reis 2004: 53; García-Entero 2005: 747). En cualquier caso, teniendo presentes las limitaciones expuestas, e intentando acomodar la distribución de usos observada a estos patrones tipológicos generales, podríamos identificar nuestro balneum dentro del esquema funcional lineal paralelo (parallel row type), con recorrido de itinerario retrógrado, ya que presenta las características generales del recorrido lineal angular -modelo especialmente presente en la Tingitana (Nielsen 1993: 69)-, aunque dispone de una sala fría de acceso apartado del resto del circuito que induce a decantarnos por la primera opción (Fig. 16A). De esta manera, los usuarios del edificio balneario accederían desde la entrada situada al norte del edificio, para pasar en primer lugar al apodyterium/frigidarium (ambiente 3), donde se limpiarían los pies y se desvestirían. De ahí podrían dirigirse o bien a la sala fría anexa al sur o al circuito caliente. La sala meridional (ambiente 2), como ya apuntamos, podría ser una sala de usos diversos, tal vez un unctorium no calefactado, si bien al margen de su funcionalidad específica, el recorrido implicaría retornar al apodyterium/frigidarium inicial para dirigirse al circuito caliente que se abre al oeste, el cual sí es ya completamente lineal, identificándose de forma continuada la presencia del tepidarium y seguidamente del caldarium, en el cual podrían disfrutar de la bañera calentada por los contiguos hornos. A la vuelta, siguiendo el esquema inverso, retornarían al distribuidor principal (apodyterium/frigidarium), donde los usuarios podrían darse un baño en la piscina fría situada en el vértice noroccidental (P-3) antes 
A

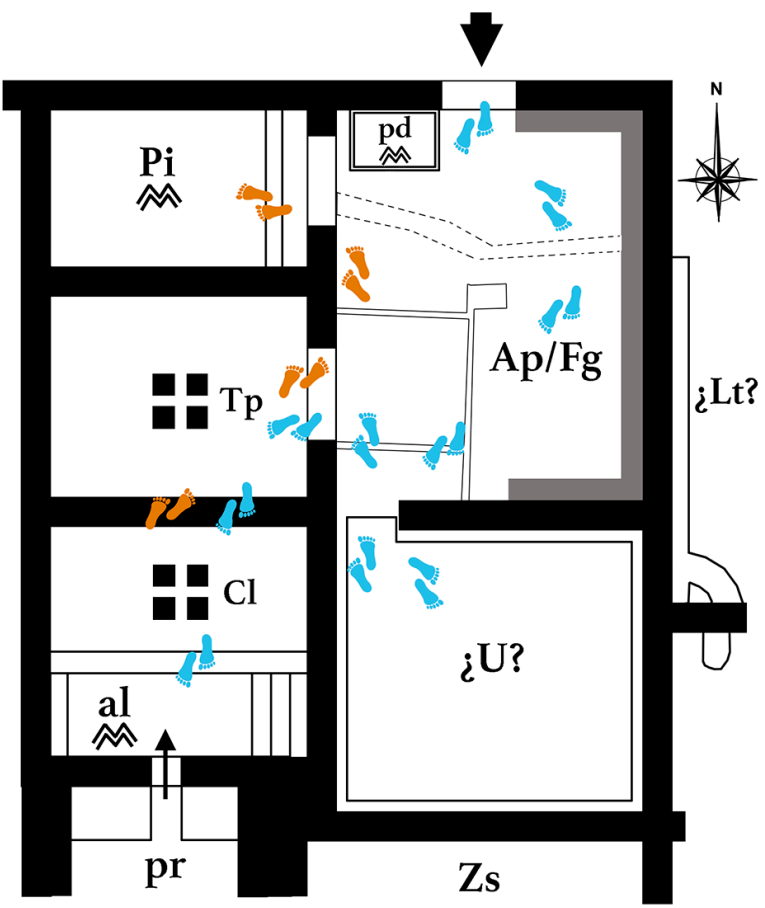

B

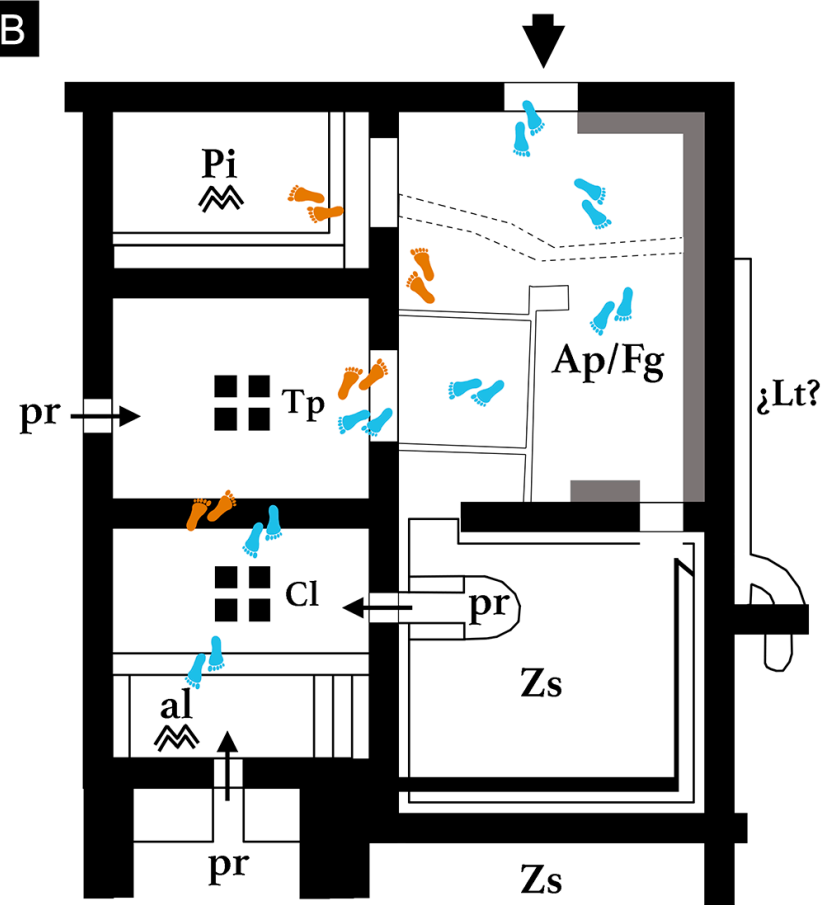

Figura 16. Plantas esquemáticas del balneum con la indicación del circuito de uso (pisadas azules -ida- y naranjas -vuelta-) y la codificación de cada sala basada en Nielsen (1993: vol. 2) y la actualización realizada por Reis (2004: 60). Planta original (A) y planta tras las reformas (B).

de volverse a vestir y finalizar el recorrido. Entre los ejemplos conocidos, tal vez uno de los paralelos más claros a nivel funcional, debido a que responde a una misma sencillez estructural, es el balneum doméstico de la casa ${ }^{\circ}{ }^{\circ} 1$ de Clunia (García-Entero 2005: fig. 202), así como los baños iniciales de Volubilis (Nielsen 1993: vol, 2, fig. 130), en la Tingitana, si bien existen también ejemplos de circuitos afines dentro del ámbito de los balnea campamentales, en un marco temporal análogo, como los presentes en los castella britanos de Aesica (Greatchesters), Vindolanda (Chesterholm, Inglaterra) (Nielsen 1993: vol. 2, figs. 135 y 140) o en los dacios de Malaiesti o Arutela (Tentea 2018: fig. 2) (Fig. 17).

Este edificio, como ya hemos apuntado, sufriría una importante reforma que hemos fechado entre finales del s. III e inicios del s. IV d. C. que simplificaría la circulación de usos del balneum, condicionada por la introducción de dos nuevos hornos -al oeste del tepidarium y al este del caldarium - que reforzarían la calefacción de las salas, en aparente disonancia con la tendencia general observada a partir del s. III que muestra una ampliación generalizada de los espacios fríos frente a los calefactados (Reis 2004: 41). De esta manera, el circuito pasaría a ser claramente lineal angular ya que implicaría el acceso por el apodyterium/frigidarum, que mantendría su actividad, y de ahí se accedería tanto a la contigua piscina fría (P-3) como a la secuencia de salas calefactadas, que se mantendrían en uso. El espacio segregado de este nuevo circuito sería la sala meridional (ambiente 2), que perdería su uso inicial y pasaría a convertirse en sala de servicio, que incluiría el nuevo horno del caldarium (Fig. 16B).

\section{Propuesta de restitución volumétrica. Nuevas tecnologías aplicadas al estudio del balneum oriental: levantamiento 3D, drones y microestratigrafía}

El proceso de investigación de un equipamiento tan complejo y diversificado como es un edificio termal solo permite aspirar a los resultados merecidos si se aplica un enfoque interdisciplinar a su estudio, entendido como una integración y colaboración de distintas disciplinas científico-técnicas, en la cual la arqueología es la herramienta de trabajo primaria a partir de la cual se han de imbricar las diferentes técnicas de estudio y aproximación a la problemática del balneum, de manera que podamos obtener el máximo caudal informativo posible. En este sentido, queremos destacar algunas de las técnicas usadas, como son la utilización de RPAS-Drones, el renderizado y la fotogrametría de los testimonios 


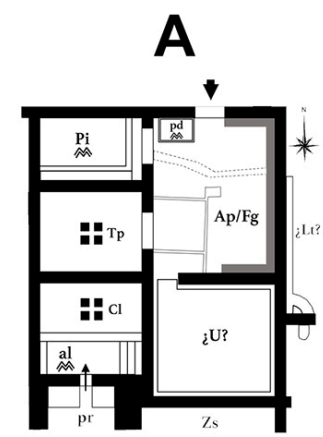

Tamuda

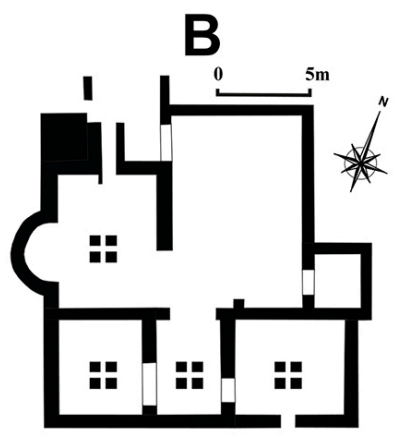

Malaiesti

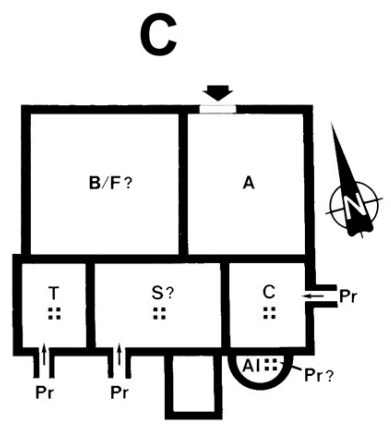

Bumbesti

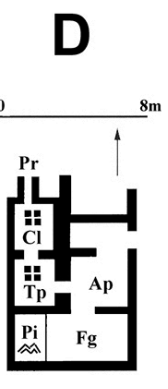

Clunia

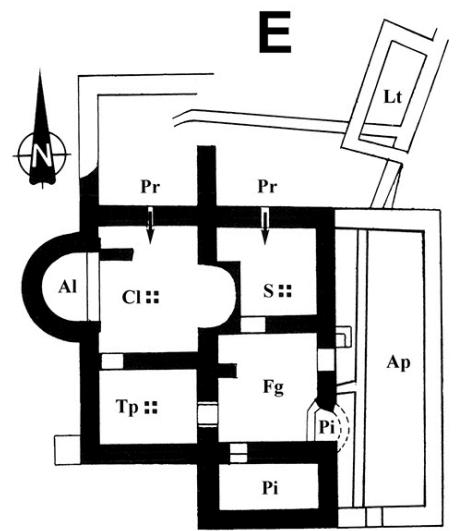

Vindolanda

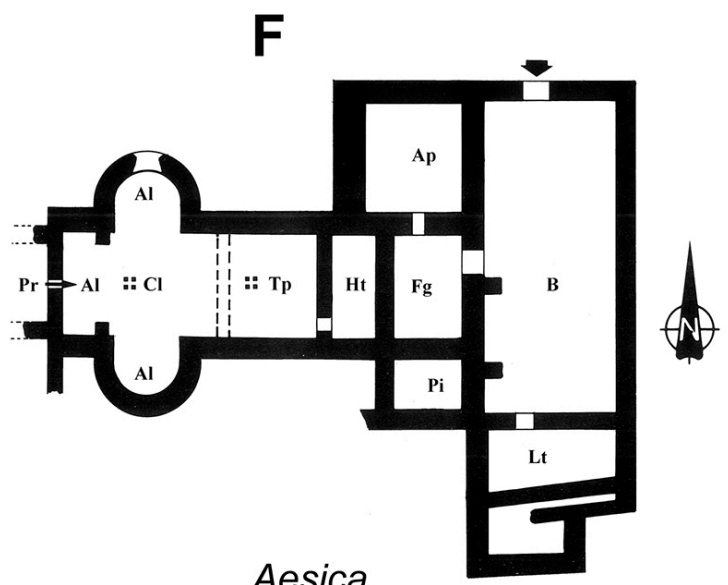

G

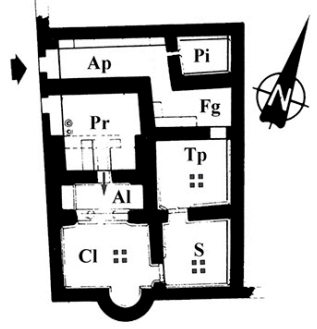

Volubilis

Figura 17. Paralelos del balneum oriental: balnea de Tamuda (A), Malaiesti (B), Bumbesti (C), Clunia (D), Vindolanda (E), Aesica (F) y Volubilis (G). Elaborado a partir de García Entero (2005: 780), Nielsen (1993: 127-137, vol. 2) y Tentea y Burkhardt (2017: 51).

arqueológicos, la topografía digital o el levantamiento volumétrico 3D. Además de estas técnicas basadas en la documentación digital, es necesario llamar la atención sobre otras disciplinas científicas donde palinólogos, geomorfólogos, microbiólogos y otros especialistas contribuyen a obtener datos invisibles al ojo humano pero que revierten de igual manera en la compresión integral del bien. La aproximación al tipo de combustible de los hornos que calientan la estructura, el análisis de los residuos de los desagües o el estudio de la microestratigrafía interna, todos ellos en marcha, nos permitirán trazar en el futuro una visión integrada y multifocal del edificio objeto de estudio.

En el caso que presentamos, la restitución volumétrica del edificio ha emanado de la suma de las disciplinas mencionadas asociadas a la generación de una documentación digital de gran precisión y al análisis funcional y estructural del edificio. En este sentido, debemos destacar que en lo que respecta a los acabados de más difícil documentación primaria, como ocurre con las techumbres, a la hora de realizar dicho levantamiento 3D se ha optado por incluir acabados compatibles con los registros documentados aquí y con los paralelos existentes referidos a este edificio (Fig. 18). Por ejemplo, para las salas frías hemos establecido un único eje a dos aguas asociado a techumbres planas, ya que no disponemos de evidencia alguna de posibles bóvedas, las cuales además no resultan necesarias dada la sencillez y austeridad general del complejo termal, por lo que creemos que habrían prescindido de ellas. Para el eje occidental, en lo que respecta a las salas calefactadas, defendemos el uso de cubierta de bóveda nervada en "armchair voussoir" atendiendo a las reconstrucciones planteadas, en asociación a la cual hemos añadido un techo de madera a dos aguas sin bóveda suspendida (Figs. 18C y 18D), coherente con los hallazgos de restos de techumbre carbonizados de las termas de Zac des Halles, en Nimes; o en los baños lusos del este de Mirobriga, ambos en asociación con este tipo 
A

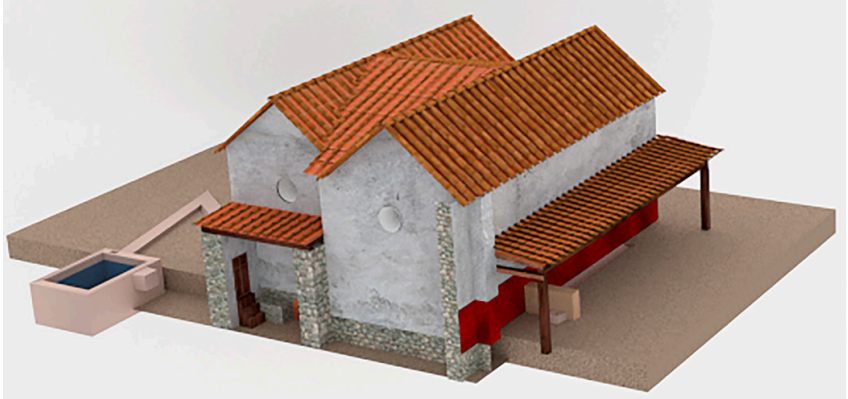

C

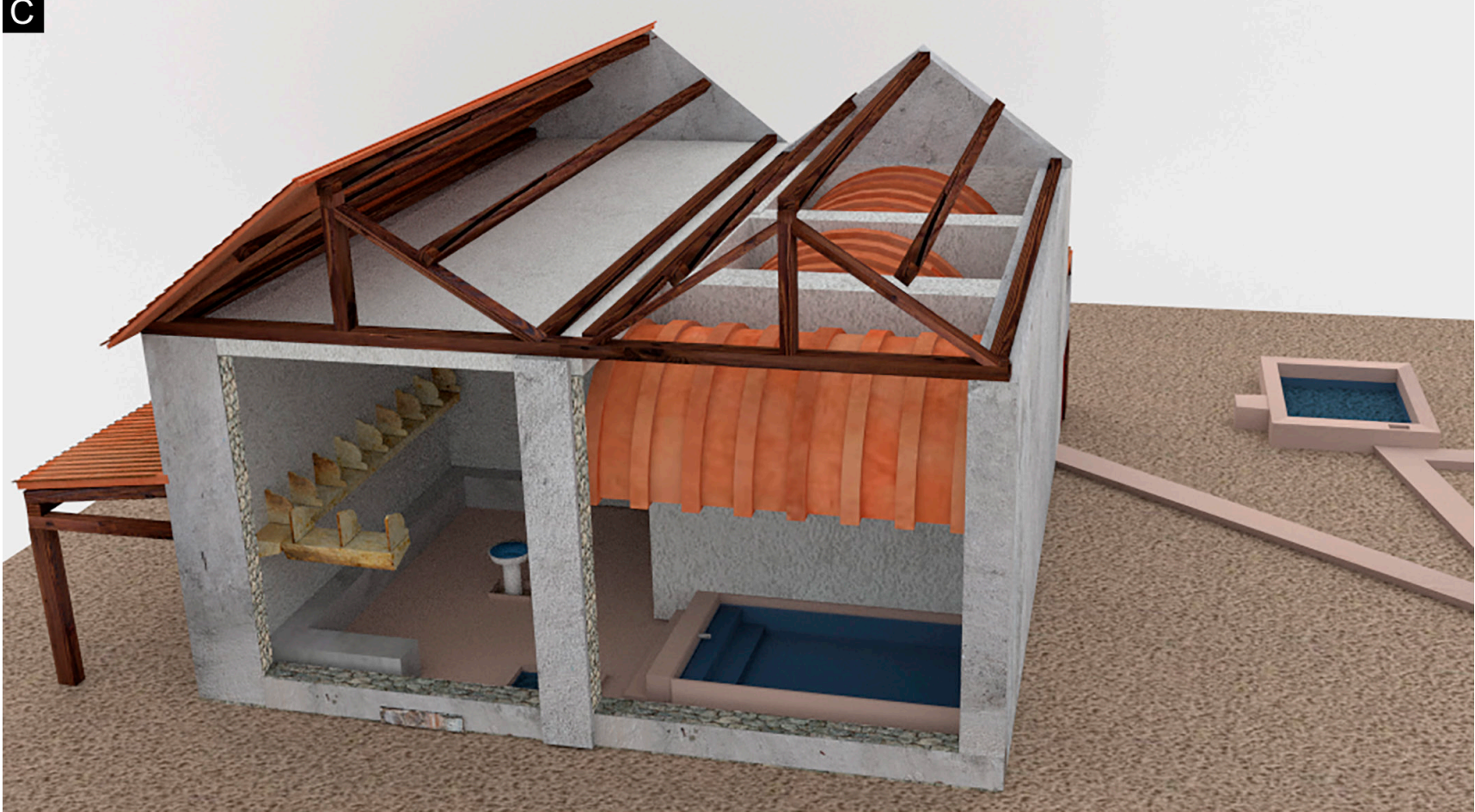

D

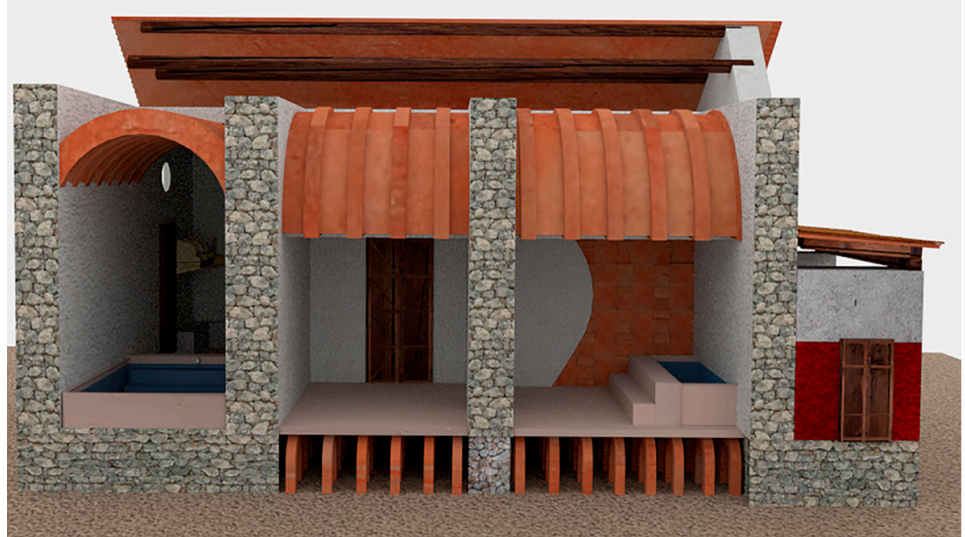

E

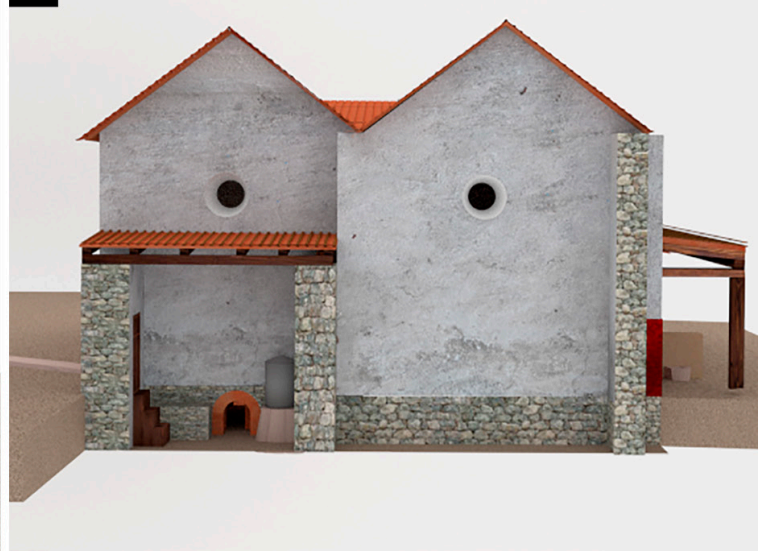

Figura 18. Levantamiento 3D del balneum oriental de Tamuda. Se muestra una panorámica general del edificio y la pileta contigua desde el sureste (A); vista exterior desde el noreste (B); aproximación al interior del edificio donde se aprecian las cubiertas interiores abovedadas, la piscina fría y los complementos del apodyterium/frigidarium (C); vista de la sección del edificio desde el oeste, donde se observa el interior de las salas calefactadas (D); y vista general desde el sur que permite apreciar el propnigeum principal (E). Autoría: Cristina Gómez. 
de bóveda, y compatible con los análisis estructurales realizados por Lancaster para las termas de Cemenelum (Niza), que compartía este mismo sistema de sustentación (Lancaster 2015b: fig.4, 460-461). La piscina fría la hemos rematado igualmente con una bóveda en sentido perpendicular, atendiendo a la orientación de su acceso, como es habitual, lo cual no ha impedido disponer de una cubierta corrida (Figs. 18C y 18D). El uso de este mismo sistema de bóveda nervada también ha sido constatado en salas frías para aligerar el peso de los arcos, y es defendido por Vitrubio para evitar que la humedad del agua afecte a la techumbre de madera al dispersarse entre las dobles bóvedas que genera este sistema (Vitrubio, De Architectura, 5.10.3). Los dos ejes definidos por la cubierta general deberían quedar articuladas entre sí por un eje central que favoreciera la evacuación del agua de lluvia hacia el norte y sur, tal como hemos representado. Finalizando el sistema de cubriciones, para las zonas de servicio perimetrales al edificio principal hemos planteado una cubrición de madera y teja a un agua tanto en las zonas que consideramos abiertas como las cerradas (propnigea), una propuesta más sencilla y en línea con la limitación de registros disponibles en este sentido.

En lo que respecta al resto de detalles constructivos internos, atendemos a las propuestas derivadas del estudio general, por lo que el levantamiento general se adapta a lo ya presentado en el apartado del análisis arqueo-arquitectónico y a las propuestas de articulación del edificio original (Figs. 18C y 19A), de manera que están presentes en el apodyterium/frigidarium tanto el banco como las estanterías para la ropa, el pediluvium o el labrum situado en el eje de la sala. En lo que respecta a la piscina se recrean las dimensiones y cubriciones propuestas, y se ha añadido un surtidor en su cabecera, ya que es el extremo por el que llegaría el suministro hídrico. El circuito calefactado dispone de los sistemas de hipocausis con las dimensiones propuestas y las cadencias de pilae descritas en líneas precedentes, detallándose en el caso del caldarium la presencia del alveus situado en el extremo sur (Figs. 18D y 19A). Los hornos han sido reproducidos atendiendo a los detalles edilicios observados y los testimonios del praefurnium, junto con algunas propuestas como la incorporación de una caldera en uno de los brazos que abrazan el praefurnium como es coherente en otros ejemplos análogos (Fig. $18 \mathrm{E})$, si bien hemos respetado también la parcialidad del registro, por lo que no hemos recreado el cierre de estos espacios de servicio meridionales. En último lugar, hemos incorporado la canaleta exterior oriental, cubierta
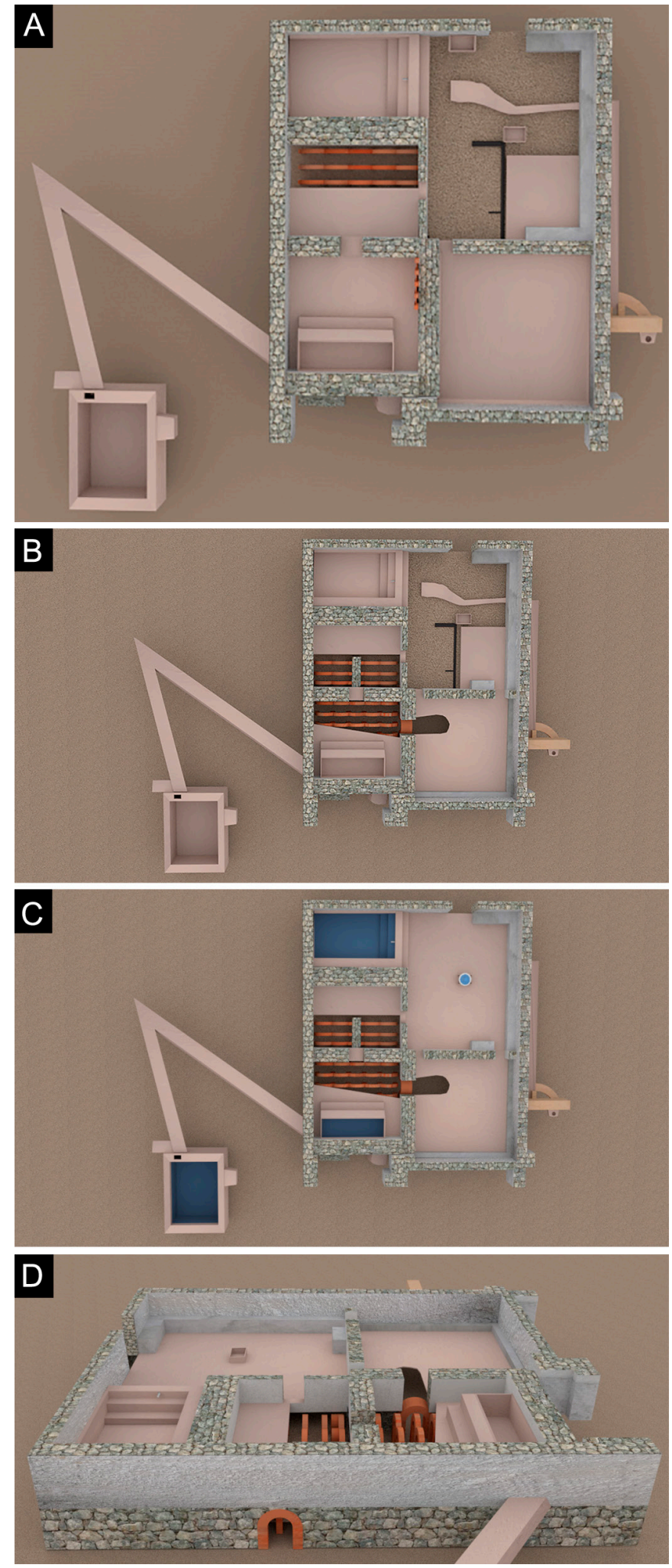

Figura 19. Levantamientos 3D del balneum oriental de Tamuda, que muestran tanto la reconstrucción de la planta general en su fase inicial (A) como diferentes vistas de detalles de las reformas llevada a cabo en el mismo edificio con posterioridad (B-D). Autoría: Cristina Gómez. 
de un espacio porticado que hemos añadido como complemento que debería disponer en el caso de tratarse de un espacio utilizado como latrinae, si bien a nivel estructural nos hemos ceñido a recrear el resto de los contextos documentados. A la hora de plantear las reconstrucciones volumétricas no hemos obviado la historia de reformas documentadas en el edificio, por lo que hemos llevado a cabo un segundo levantamiento que muestre el interior del edificio una vez llevadas a cabo las distintas modificaciones estructurales documentadas y ya presentadas en líneas precedentes centradas principalmente en la inserción de nuevos praefurnia, el reforzamiento del hipocaustum de la sala templada, la remodelación de la piscina fría, la supresión del pediluvium y el reaprovechamiento de la sala fría como espacio auxiliar (Figs. 19C y 19D).

\section{LOS BALNEA EN INSTALACIONES MI- LITARES Y EL CASO DE TAMUDA}

El baño es un equipamiento de ocio e higiene, pero también es concebido como instrumento de romanización (Nielsen 1993: 35), en especial cuando se ponía a disposición de los integrantes de las cannabae, por lo que su presencia en los campamentos auxiliares situados en las fronteras del Imperio cobra una significación especial. Esto explica que la existencia de instalaciones termales no suponga una excepción dentro de los equipamientos habituales presentes en los campamentos militares del limes, si bien siempre existen voces que consideran los baños como una distracción que se contrapone a los valores de la disciplina militar (Vega 2010: 304), algo que se aleja de lo que muestran los testimonios arqueológicos. Así, mientras que en los grandes campamentos asociados al establecimiento de legiones es habitual observar la construcción de grandes thermae, en su mayoría dentro de sus límites murarios, en los castella vinculados a tropas auxiliares es frecuente encontrar balnea situados fuera de los mismos, como el caso en el que nos ocupa, si bien tampoco es anómala, aunque sí minoritaria, la documentación de este tipo de equipamiento dentro de sus murallas.

Las instalaciones balnearias dentro de los limites murarios en ocasiones estaban asociadas a un uso exclusivo vinculado al praetorium, como se ha identificado en Arbeia (Soith Shields), Isca Dumniornorum (Exeter) o Fanum Cocidii (Bewcastle) (Bidwell 1997: figs. 36, 51 y 52). En Tamuda se documentó un pequeño balneum
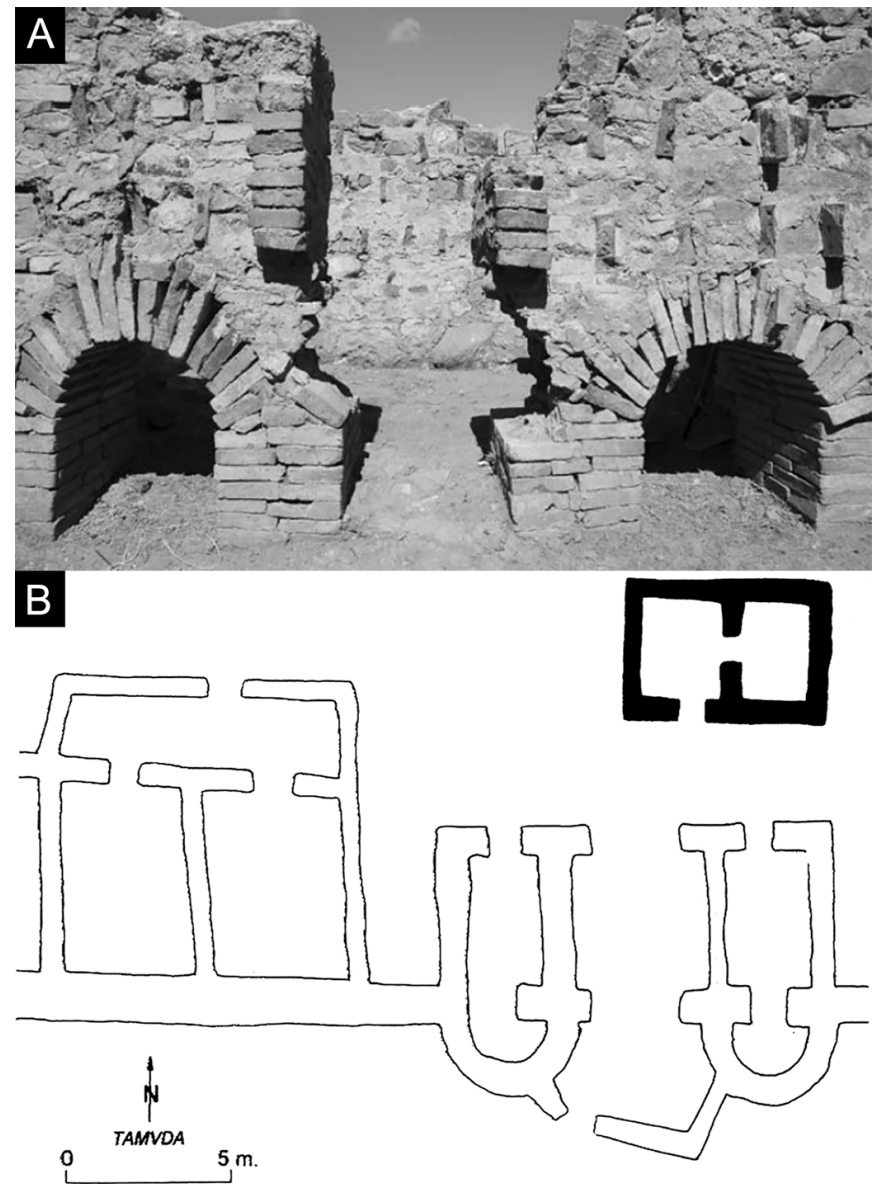

Figura 20. Balneum intra moenia de Tamuda. Foto del muro divisorio de las salas (A) (Campos et al. 2012: fig. 4) y planta del edificio (según Villaverde 2001: 533, lám. XVI) (B).

de apenas $25 \mathrm{~m}^{2}$ ubicado al interior del castellum, que fue instalado aprovechando la remodelación de la Porta Praetoria. Este edificio ha sido objeto de varios estudios recientes (Campos et al. 2012; Fernández et al. 2015) que han permitido identificarlo como un pequeño espacio termal formado por dos salas calefactadas - una sudatio y un caldarium-, puestas en relación con la actividad de un valetudinarium que pudo ubicarse en sus inmediaciones, a diferencia de los casos apuntados. El edificio se erigió en época antoniniana avanzada o primo-severiana (150-225 d. C.) (Bustamante et al. 2013: 317-347), existiendo más dudas en torno a su cese de actividad, ya que los autores del primer estudio lo sitúan a inicios del s. IV (Campos et al. 2012: 241), mientras la colmatación inicial del pavimento de acceso al edificio parece mantenerse en uso aún a inicios de la quinta centuria (Bustamante et al. 2013: 340). Esta instalación termal (Fig. 20), de pequeño espectro, no pudo dar servicio a la generalidad de la dotación del castellum, por lo que 
el balneum del barrio oriental de Tamuda, situado fuera de sus murallas, sería el principal equipamiento balneario del asentamiento, como era habitual documentar en este tipo de fuertes auxiliares.

Esta ubicación mayoritaria, segregada de las instalaciones militares, se debe a varios factores, llamando la atención en primer lugar el hecho de que esta disposición permite evitar riesgos de incendio derivados de la constante combustión de los hornos termales, aislándolo así del resto de instalaciones castrenses. Por otra parte, su localización externa permite disociar el ocio de la rutina militar, y reservar el espacio protegido intra moenia para equipamientos estratégicos esenciales, entre los que no se contemplarían estos baños. En tercer lugar, a la hora de su ubicación, se debe tener en cuenta la facilidad de captación y drenaje hídrico, una cuestión relevante en este tipo de equipamientos, y motivo por el cual muchos de estos edificios termales se asientan en terrazas fluviales próximas a sus fuertes. En último término, como defiende Sommer (1984: 15-43), la situación externa de estos balnea en ocasiones es aislada aunque bajo la protección del fuerte, pero en otros casos estos equipamientos se asocian a la presencia de otras construcciones civiles o militares vinculadas a las cannabae o a la presencia de un vicus anexo, convirtiéndose por tanto en instalaciones que pueden ofrecer un servicio civil/militar, que estarían planificados desde un inicio atendiendo a las necesidades del campamento y del vicus anexo.

La ubicación del balneum del barrio oriental de Tamu$d a$ respondería a varios de estos factores que acabamos de presentar, ya que se sitúa en un extremo del asentamiento, junto al arroyo Uad Sequin o Tamuda que, como ya apuntamos, constituiría un recurso hídrico a la vez que un punto de desagüe, cuestiones claves para el funcionamiento de estas instalaciones. En el barrio oriental de Tamuda hemos documentado igualmente numerosas edificaciones del urbanismo previo al establecimiento del campamento, pero también hemos identificado otras construcciones coetáneas y accesorias al castellum, como el foso perimetral del fuerte, edificios dedicados a la estabulación y otras estructuras todavía por definir (Bernal-Casasola et al. 2019: 73-76), pero que en cualquier caso van permitiendo articular la dimensión de las cannabae que, sin duda, existirían en el entorno del campamento, y a las cuales también podría estar dando servicio este equipamiento termal (Fig. 2B) (Bernal-Casasola et al. 2018a: fig. 7b) de manera que posiblemente se asemejasen a la configuración de otros campamentos auxiliares como el de Vindolanda (Chesterholm, Inglaterra), un ejemplo muy cercano al nuestro, cuyo balneum situado fuera de las murallas tenía $310 \mathrm{~m}^{2}$, no muy distantes a los $224 \mathrm{~m}^{2}$ del de Tamuda, y se integraban también en unas cannabae bien desarrolladas en su entorno. En la Tingitana observamos otros ejemplos de baños situados en el perímetro de campamentos militares asociados al uso de sus tropas, como muestran los baños del castellum de Tremuli (Zoco Al-Arba del Garb) -al norte de Banassa- (Euzennat 1989: 35-55), siendo especialmente significativo el caso del castellum de Tocolosida, -en el entorno de Volubilis- destacando este último caso al documentarse un edificio termal de similares cronologías al nuestro, tan solo unos $40 \mathrm{~m}$ al exterior del castellum, y asociado al vicus anexo, que se vincula expresamente al uso de sus tropas (Euzennat 1989: 240-255). En cuanto a organización espacial, el ejemplo más representativo es el del asentamiento tingitano de Thamusida, donde en este caso distinguimos un gran campamento militar que dispuso de unos baños exteriores situados junto al río, vinculados a la presencia de un vicus anexo, y que en su fase más antigua -de época trajanea/adrianea- presentaba unas dimensiones muy similares a nuestros baños $\left(175 \mathrm{~m}^{2}\right)$, si bien con posterioridad evolucionan de forma exponencial al igual que el propio asentamiento (Rebuffat et al. 1970: 161-168, fig. 18).

El balneum oriental de Tamuda, como hemos visto, se sitúa fuera de las murallas del castellum, a $88 \mathrm{~m}$ al este de las mismas y muy próximo a un arroyo contiguo. La búsqueda de otros paralelos entre los campamentos de similares características en otros puntos del limes romano no resulta compleja para este tipo de edificios, que parecen responder a una planificación similar generalizada. Entre los ejemplos britanos, posiblemente los mejor estudiados, podemos destacar en cuanto a su ubicación el balneum del castellum de Kanovium, un fuerte auxiliar de una cohors equitata que disponía de unos baños localizados a unos $50 \mathrm{~m}$ a la salida de Porta Praetoria, al igual que en Tamuda (Campbell 2009: 28); aunque también son paralelizables los balnea de los castella de Labatris (Bowes), Glannoventa (Ravenglass), Cilurnum (Chesters) (Vega 2010: 310-311) o Bothwellhaugh (Lanarkshire, Escocia) (Keppie 1981: 41-49), por poner algunos ejemplos significativos que disponían de balnea externos asociados a ríos o afluentes cercanos. En el limes de Dacia encontramos numerosos ejemplos de balnea localizados entre medio y un centenar de metros fuera de las murallas de sus castella, de cronologías similares al nuestro, y situados en las terrazas de ríos contiguos, al igual que el caso tamudense, como mues- 
tran los casos de Mehadia o Canutele, cuyos balnea se sitúan a $100 \mathrm{~m}$ a levante del fuerte y en las terrazas de los ríos Belareca y Motru; los de Romita (adyacente al río Agris), o Slaveni (junto al río Olt), y así en más de una docena de ejemplos análogos recopilados por Tentea y Burkhardt (2017: 15-52). Sin embargo, de entre todos ellos, posiblemente el mejor ejemplo sea el del castellum de Malaiesti (Prahova, Rumania), fuerte auxiliar de 2,7 ha, de época de Trajano, cuyo balneum se situaba a unos $70 \mathrm{~m}$ de las murallas, en la terraza del río Varbilao (Fig. 17B). El edificio balneario se corresponde con una estructura muy cuadrada como en nuestro caso -de $15 \mathrm{~m}$ de lado- dentro de la cual se distribuyen las estancias, contando en este caso con un mayor porcentaje de salas climatizadas. Llama la atención en último lugar, que tras su abandono se halló entre sus restos un enterramiento (Rusu et al. 2019: fig. 1), al igual que hemos documentado en la última campaña del balneum de Tamuda, evidencia del reaprovechamiento de estas estructuras tras su abandono, como fue habitual en las zonas fronterizas tras el desmembramiento de las estructuras imperiales.

En el limes oriental tenemos ejemplos similares, aunque muchos de ellos relacionados con fases más avanzadas a nivel temporal. Destacamos en este sentido los pequeños castella de la zona del Jordán, como el de Osial Costia (Yotvata), Tamara (Hazeva), o el de Arieldela (Ayn Gharandal), asociados a la protección de oasis o stationes caravaneras, los cuales disponen de balnea situados a 50$60 \mathrm{~m}$ de sus murallas, algunos de ellos con un estado de conservación excepcional (Darby 2015: 76-79), que en cualquier caso sirven como ejemplo de la generalización de la ubicación externa de este tipo de equipamientos frente a campamentos de reducidas dimensiones.

En lo que se refiere a la dualidad que observamos en Tamuda, que cuenta con dos instalaciones balnearias, debemos apuntar que esta situación tampoco es anómala (Vega 2010: 310), especialmente si valoramos la escasa entidad del testimonio situado intra moenia, ya que el mismo carece de salas de baño, lo que limita sus necesidades de captación y evacuación hídrica, y además parece asociarse a un edificio dedicado a fines terapéuticos, por lo que podría disponer de un uso restringido frente a las mayores capacidades del balneum exterior. Un caso análogo es el del ya citado castellum de Bothwellhaugh, de similar datación, y donde igualmente está presente un balneum intra moenia, que se asocia al uso de los mandos del fuerte; mientras existe otro situado a $100 \mathrm{~m}$ de la muralla y cerca del río (Keppie 1981: 46-91) como el que traemos a colación.

\section{Los balnea o balinea campamentales. Una reflexión conceptual}

No es el objetivo de este trabajo realizar un análisis in extenso sobre la definición terminológica utilizada para la identificación de los baños tamudenses del barrio oriental que son objeto de estudio de este trabajo, y que aquí integramos dentro de los balnea frente a otras posibles identificaciones. Sin embargo, creemos que es necesario atender, aunque sea de forma somera a esta problemática, dada las derivaciones conceptuales y morfológicas asociadas a uno y otro tipo de instalaciones termales que vienen siendo identificadas como thermae o balnea.

En primer lugar, debemos partir de la diferenciación que realiza Nielsen (1993: 3), quien identifica como thermae a las instalaciones monumentales y simétricas que disponen de equipamientos de ocio como las palestras; mientras restringe el término de balnea a los baños públicos más modestos y a otras instalaciones privadas. Muy interesante en torno a esta cuestión es un artículo de Maréchal (2012: 146), quien defiende la ambigüedad y artificiosidad de la diferenciación aplicada a ambos términos por los investigadores más influyentes (Nielsen 1993: 3; Gros 1996: 388), y se decanta por la que tiende a definir los balnea como los equipamientos más sencillos, modestos o ausentes de decoración, mientras con thermae se refiere a las más lujosas y artísticas construcciones. También debemos recordar que esta diferenciación terminológica deriva del origen de cada vocablo, ya que mientras balnea es el término latino, therma procede del griego, del que parte la identificación. Partiendo de cualquiera de los dos planteamientos esgrimidos tenemos claro que por sus características menos monumentales y por la austeridad que evidencia el edificio tamudense encajaría dentro del grupo de los balnea.

Pero existe un tercer elemento de sustento para esta identificación, basado en la amplia colección de referencias epigráficas halladas en el limes que aluden a la presencia de baños situados en campamentos militares, los cuales son identificados recurrentemente como balnea o balinea. En muchos de estos casos estas referencias aparecen en inscripciones conmemorativas dedicadas a construcciones o reparaciones en este tipo de edificios asociados a instalaciones militares, como la documentada en el cercano castellum tingitano de Ain Schkur, al norte de Volubilis (Euzennat 1989: 225-274), la hallada asociada al campamento de Lavatris (Bowes, Inglaterra) (CIL 7, 273), o la alusiva a la cohors II Fla- 


\begin{tabular}{|c|c|c|}
\hline Referencia* & Texto referido al edificio termal & $\begin{array}{l}\text { Contingente militar (localización) y datación } \\
\text { de la inscripción }\end{array}$ \\
\hline $\begin{array}{l}\text { Euzennat } \\
\text { 1989: p. 314) } \\
\end{array}$ & $\begin{array}{l}\text {...balneum vet(us?) vetustate conlapsum a } \\
\text { fundamentis restituit, exampliata priore cella... }\end{array}$ & $\begin{array}{l}\text { IIII Cohorte milliaria Tungrorum (Castellum de } \\
\text { Ain Schkur, Marruecos) 232-233 d.C. }\end{array}$ \\
\hline $\begin{array}{l}\text { AE } 1930 \\
0114\end{array}$ & $\begin{array}{l}\text {...erat humo copert(um) et in labe }(\mathrm{m}) \\
\text { conl(apsum) et princ(ipia) et bal(neum) } \\
\text { rest(ituit)... }\end{array}$ & $\begin{array}{l}\text { Cohorte (Castellum de Banna, Birdoswald, } \\
\text { Inglaterra) } 297 \text { d.C. }\end{array}$ \\
\hline CIL VII, 273 & $\begin{array}{l}\text {...balineum vi ignis exustum coh(orti) I } \\
\text { Thracum restituit... }\end{array}$ & $\begin{array}{l}\text { I Cohorte Thracum. Ala de cabalería Vettonum } \\
\text { (Castellum de Lavatris, Bowes, Inglaterra) 197- } \\
194 \text { d.C. }\end{array}$ \\
\hline CIL VII, 445 & ...balneum cum basilica a solo instruxit... & $\begin{array}{l}\text { I Cohorte Lingorum (Castellum de Longovicium, } \\
\text { Lanchester, Inglaterra) 238-244 d.C. }\end{array}$ \\
\hline CIL VII, 984 & ...explicito balineo... & (Castellum de Risingham, Inglaterra). Romano. \\
\hline CIL VII, 287 & $\begin{array}{l}\text {...balineum refect(um) [et] basilicam vetustate } \\
\text { conlabsum a solo restitutam... }\end{array}$ & $\begin{array}{l}\text { Ala Sebussiana de caballería (Fuerte de } \\
\text { Lancaster, Inglaterra) 262-266 d.C. }\end{array}$ \\
\hline $\begin{array}{l}\text { AE 1986, } \\
00523\end{array}$ & $\begin{array}{l}\text { Fortunae Brittones Elantienses balineum } \\
\text { vetustate conlabsum adiecta concha et camaris } \\
\text { opere figlino restitutis... }\end{array}$ & $\begin{array}{l}\text { Legión VIII Augusta (Civitas Alisinensium, } \\
\text { Neckarburken, Alemania)158 d.C. }\end{array}$ \\
\hline \begin{tabular}{|l} 
CIL XIII, \\
06592
\end{tabular} & $\begin{array}{l}\text { Deae Fortuna[e] sanctae balineu[m] vetustate } \\
\text { conlapsum expl(oratores)...restituer(unt). }\end{array}$ & $\begin{array}{l}\text { Legión XII Primigenia Pia Fidelis (Civitas } \\
\text { Alisiensium, Walldürn, Alemania) } 232 \text { d.C. }\end{array}$ \\
\hline \begin{tabular}{|l|} 
CIL XIII, \\
11795 \\
\end{tabular} & In[stit]uit... in prae[torium]...et in baln[eum]... & $\begin{array}{l}\text { I Cohorte Septima Belgrarum (Öhringen, } \\
\text { Alemania) } 241 \text { d.C. }\end{array}$ \\
\hline \begin{tabular}{|l|}
$\mathrm{AE} 1995$, \\
1165 \\
\end{tabular} & $\begin{array}{l}\text {...balneum coh(ortis) I Ger(manorum) } \\
\text { vetustate dilabsum a solo restitutum... }\end{array}$ & $\begin{array}{l}\text { I Cohorte Germanorum (Jagsthausen, Alemania) } \\
\text { 197-209 d.C. }\end{array}$ \\
\hline \begin{tabular}{|l|} 
CIL XIII, \\
06562 \\
\end{tabular} & $\begin{array}{l}\text {...balineum coh(ortis) I Germ(anorum)... } \\
\text { vetustate conlabsum restituerunt... }\end{array}$ & $\begin{array}{l}\text { I Cohorte Germanorum (Jagsthausen, Alemania) } \\
244-247 \text { d.C. }\end{array}$ \\
\hline \begin{tabular}{|l} 
CIL XIII, \\
06552 \\
\end{tabular} & $\begin{array}{l}\text { In h(onorem) d(omus) d(ivinae) Deae Fortunae } \\
\text { sanct(a)e balineari reduci... }\end{array}$ & $\begin{array}{l}\text { I Cohorte Germanorum (Jagsthausen, Alemania) } \\
248 \text { d.C. }\end{array}$ \\
\hline CIL III, 789 & $\begin{array}{l}\text { Fortunae Reduci Ael(ius) Celer praef(ectus) } \\
\text { eq(uitum) alae Front(onianae) ob restitutionem } \\
\text { balinei posuit }\end{array}$ & $\begin{array}{l}\text { Ala I Tungrorum Frontoniana (Arcobara, Uriu, } \\
\text { Rumanía) 151-200 d.C. }\end{array}$ \\
\hline CIL III, 1374 & $\begin{array}{l}\text {...balneas coh(ortis) II Fl(aviae) } \\
\text { Commag(enorum) vetustate dilabsas restituit... }\end{array}$ & $\begin{array}{l}\text { II Cohorte Flavia Commagenorum (Micia, Vetel, } \\
\text { Rumanía) } 193 \text { d.C. }\end{array}$ \\
\hline CIL III, 7473 & $\begin{array}{l}\ldots[\text { [b]alna } \operatorname{coh} \text { (ortis) II Fl(aviae) Britt(onum) } \\
{[\text { Alexa]n[d]rianae a } \text { so }<\text { l }>\text { o restitutae ... }}\end{array}$ & $\begin{array}{l}\text { I Cohorte Flavia Brittonum (Castellum de } \\
\text { Sexaginta Prista, Ruse, Bulgaria) } 230 \text { d.C. }\end{array}$ \\
\hline $\begin{array}{l}\text { AE 1903, } \\
0066\end{array}$ & $\begin{array}{l}\text {...balnea[s coh(ortis) II Fl(aviae) } \\
\text { Commagenor(um] Severia[nae vetust(ate) } \\
\text { dilapsas res]tituit... }\end{array}$ & $\begin{array}{l}\text { II Cohorte Flavia Commagenorum (Micia, Vetel, } \\
\text { Rumanía) 222-235 d.C. }\end{array}$ \\
\hline $\begin{array}{l}\text { AE 1950, } \\
0127 \\
\end{array}$ & $\begin{array}{l}\text {...balneum } v[\text { etustate corrup]tum restituendum } \\
\text { [curavit]... }\end{array}$ & I Centurión (Thenadassa, Ain Wif, Libia) Romana. \\
\hline
\end{tabular}

Figura 21. Tabla con las referencias epigráficas asociadas a campamentos o destacamentos romanos en los que se cita la presencia de balnea o balinea, a partir de Euzennat (1989: 314), Nielsen (1993: 75, vol. 1), Perea (1997), Campbell (2009: 314) y Vega (2010: 307).

\section{PROPUESTA DE PUESTA EN VALOR Y CUBRICIÓN DEL EDIFICIO TERMAL}

La ejecución del estudio arqueo-arquitectónico desarrollado en torno al edificio termal ha ofrecido la información pertinente y necesaria como base para trazar una propuesta de valorización que incluya el diseño de un circuito de visita y un proyecto de cubrición del balneum, sobre los que centraremos la parte final de esta exposición. Esta propuesta no puede surgir per se sin sustentarse en unos principios teóricos y metodológicos, que si bien son vertebrales, no podemos desarrollar in extenso en este apartado, habiendo sido plasmados de manera detallada en la memoria de la última campaña arqueológica (Verdugo y Ramón 2018), a la que remitimos para una consulta precisa. En cualquier caso, las directrices, estrategias y metodologías seguidas para esta intervención responden a las desarrolladas a nivel internacional: las "Cartas del Restauro" y la "Estrategia Europea de Conservación Preventiva", así como las implementadas a nivel

via Commagenorum en el fuerte dacio de Micia (Vetel, Rumania), que registraba la reparación de su destartalada casa de baños en época de Septimio Severo (CIL 3, 1374), por poner algunos ejemplos concretos de la larga lista de referencias análogas, algunas de las cuales hemos recopilado aquí (Fig. 21). Sin embargo, no podemos dejar de referir algunos ejemplos especialmente singulares, como son los datos procedentes de las tablillas de madera excepcionalmente conservadas en el castellum de Vindolanda (Chesterholm, Inglaterra), que representan un importante archivo documental de las actividades cotidianas del fuerte, y entre las que se encuentran, por ejemplo, la referencias a obreros relacionados con estos edificios (structores ad balneum) o al personal asignado al balneum, como un balniator citado en la tablilla Tab. Vindol. II 155 y 182 (Vega 2010: 304-306). nacional: los planes sectoriales desarrollados a partir de 2010 por el Instituto de Patrimonio Cultural de España para cumplir con esta última estrategia y las directrices del Plan Nacional de Conservación Preventiva español, ya que son criterios y directrices de reciente formación $\mathrm{y}$, aunque dichas metodologías y estrategias se centran en ámbito europeo y español, son conceptualmente extrapolables al contexto de Marruecos, tanto en términos de cercanía como en similitud tipológica, cronológica y cultural de los bienes arqueológicos.

Esta estrategia ha implicado que llevemos a cabo el análisis de los bienes culturales, de su estado de conservación, del uso que se hace de los mismos y de los riesgos de su deterioro, enfocados a la planificación de la conservación preventiva, base sobre la cual se han desarrollado las propuestas de conservación y la valorización del bien. 
Atendiendo a estas premisas, los criterios fundamentales a la hora de afrontar nuestra propuesta de conservación y valorización del balneum oriental de Tamuda deben tener siempre presentes los criterios fundamentales: reversibilidad, identificación, compatibilidad y documentación. El desarrollo de estos criterios requiere de una metodología que encauce la totalidad de la intervención, tanto desde el punto de vista estratégico como táctico. La metodología que hemos seguido es fruto de años de experiencia interdisciplinar en el campo de la conservación del patrimonio histórico edificado de la Dirección General de Bienes Culturales (Consejería de Cultura y Patrimonio Histórico de la Junta de Andalucía), concretamente en el Servicio de Conservación y Obras del Patrimonio Histórico, con una elaboración final a cargo de su Departamento de Programación y Proyectos.

Se trata de una metodología integral cuya flexibilidad intrínseca puede adaptarse en gran medida al programa de trabajo y a las circunstancias coadyuvantes y sobrevenidas, que parte de la identificación, diagnóstico y conocimiento del inmueble a nivel interdisciplinar como base para definir los aspectos programáticos y proyectuales de la ejecución efectiva de las obras de conservación, y finalizar con el desarrollo del programa de difusión a diferentes escalas, que facilite la lectura interpretativa y pedagógica del bien valorizado.

\section{Una propuesta de circuito de visitas del castellum y el balneum oriental}

En un yacimiento arqueológico, los circuitos de visita son esenciales para su comprensión. Un de visitas. trazado óptimo deberá mostrar los aspectos esenciales de su estructura, la percepción de su espacialidad, su materialidad, las relaciones entre las partes y su incorporación al paisaje, entre otros aspectos más concretos.

Desafortunadamente, Tamuda todavía es un yacimiento en gran medida sin investigar, con déficit de

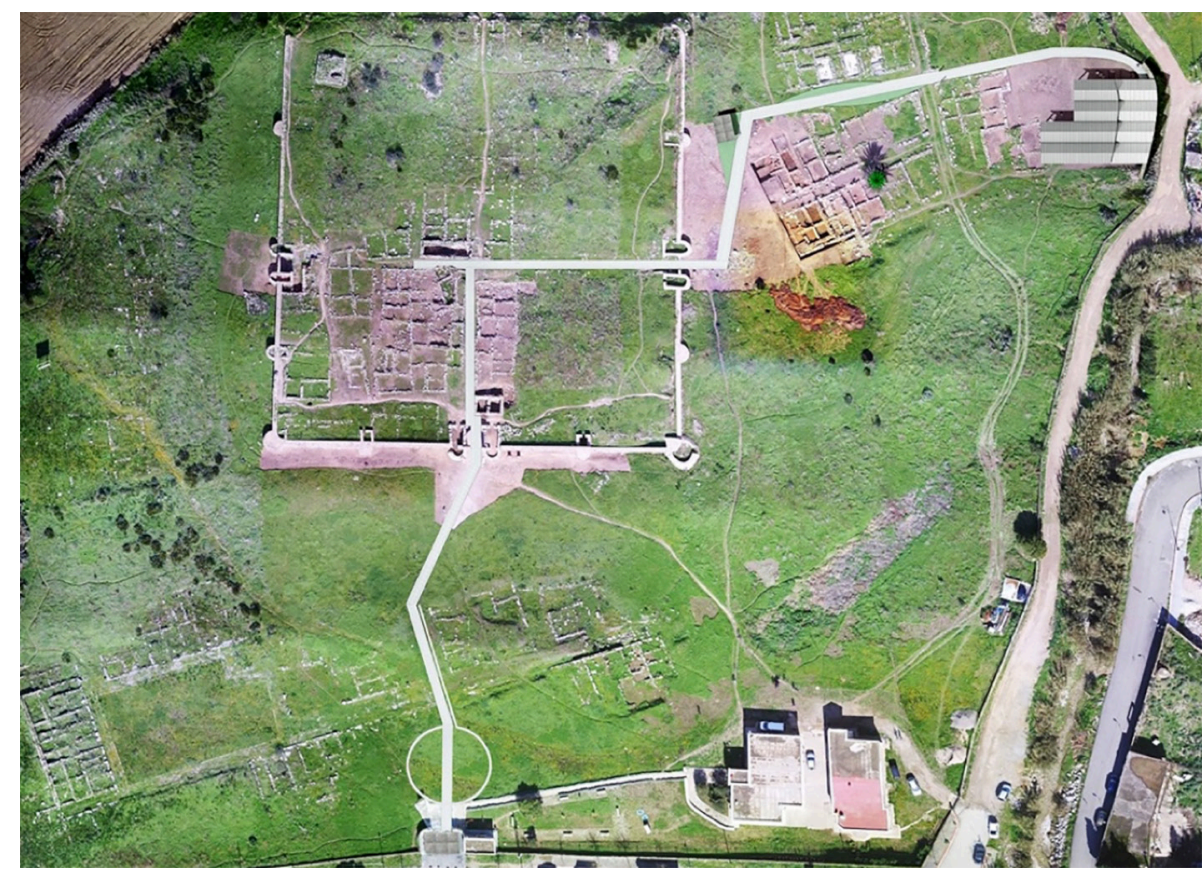

Figura 22. Propuesta de articulación e integración del balneum y su cubierta en un nuevo circuito

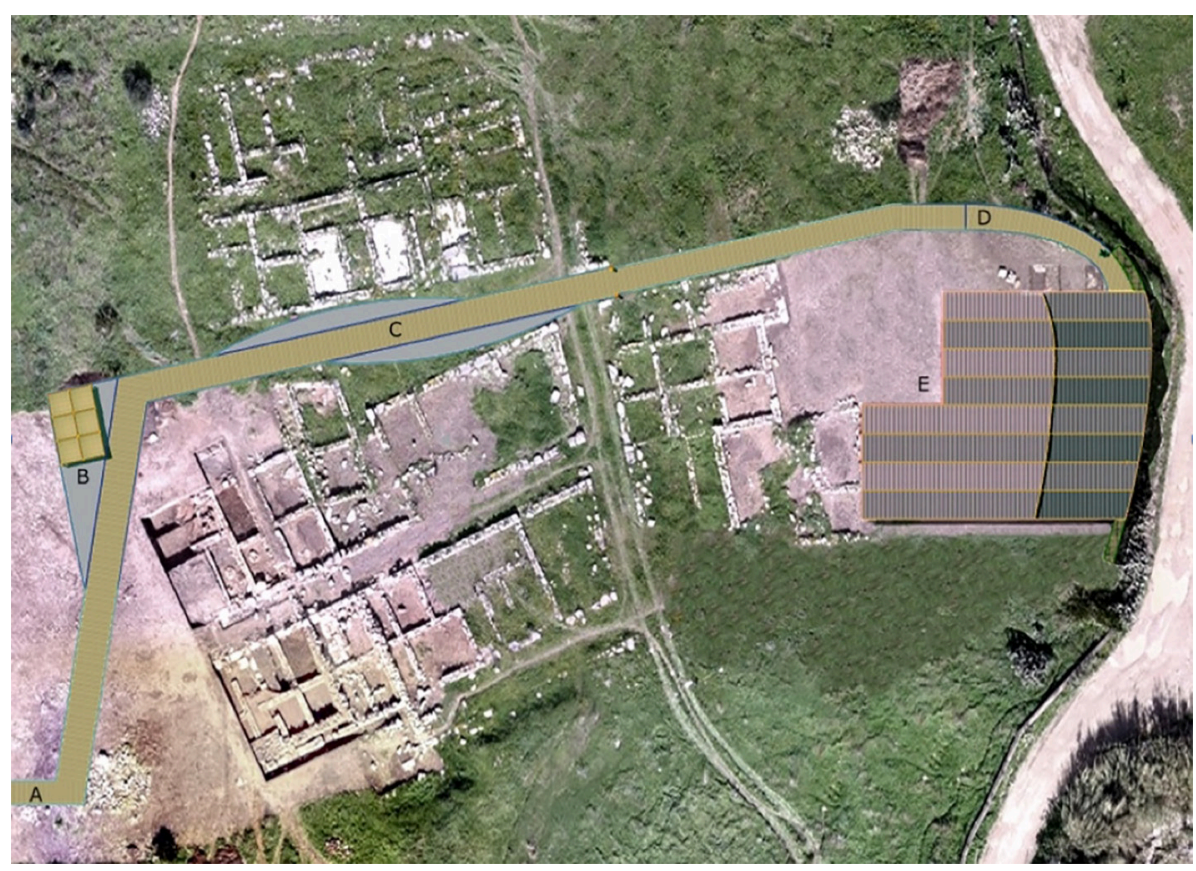

Figura 23. Detalle del acceso al balneum a través del barrio mauritano oriental. A: Acceso desde el castellum. B: Umbráculo de descanso y contemplación. C: Miradores sobre las excavaciones del barrio mauritano. D: Rampa de acceso al mirador del balneum. E: Cubierta del balneum. 
conservación y articulación de sus partes. Por ello, la propuesta respecto al balneum es acotada y debería ir de la mano del desarrollo del Plan Director del yacimiento arqueológico. Con base en ello, hemos planteado un primer circuito que centra su atención en el castellum y en los nuevos inmuebles del barrio oriental, dejando fuera de esta primera propuesta de circuito de visita los barrios norte y oeste, si bien se tiene presente una amplia flexibilidad, que permitiría su inclusión en otros circuitos de superior nivel.

El circuito planteado es de ida y vuelta, comenzaría en la entrada actual del conjunto arqueológico (Fig. 22). De forma intencionalmente quebrada, para adaptarse al urbanismo de la ciudad helenística a la que cruza, el camino alcanzaría el castellum para entrar por Porta Praetoria, el acceso sur. Tras recorrer la zona interior saldría por la puerta oriental, discurriendo por los ejes centrales junto a las estructuras más relevantes como el balneum interior o la cisterna central. Traspasada la puerta oriental con la explicación del foso campamental (Fig. 23A), la senda giraría al norte, buscando el eje del barrio púnico-mauritano para adentrarse en él. En dicha esquina se plantea una plaza de descanso (Fig. 23B), contemplación y apreciación del paisaje, con bancos y cubierta parcialmente de toldos, que adaptaría su ubicación a la presencia del foso del fuerte recientemente definido. Girando hacia la derecha, transcurre por el eje principal del barrio oriental, buscando el balneum. A ambos lados del camino se situarían sendas plataformas con forma de segmento lunar (Fig. 23C), ligeramente alzadas, que asomarían a los edificios mauritanos. Saliendo de esa zona se encaminaría al rellano del balneum, donde comenzaría la rampa curva (Fig. 23D), volada, de acceso al mismo (Fig. 23E).

Los caminos se adaptarían en lo posible a la topografía del terreno, siendo los rellenos y desmontes los imprescindibles para su conformación, y el recorrido priorizaría los elementos más destacados y cercanos al recorrido. Como material de construcción de la senda peatonal se propone el uso de piezas modulares de piedra texturada local sobre firme inerte y flexible; mientras que para las plataformas se usaría igual material pero distinto color y textura. Como complemento, durante todo el recorrido se situarían atriles, resistentes a la intemperie, con información gráfica y los textos breves necesarios para el conocimiento de los elementos.

\section{Propuesta de intervención de conserva- ción y valorización del balneum de Ta- muda}

Para la redacción de esta propuesta se han tenido en cuenta los análisis y estudios previos necesarios para completar el conocimiento del bien, sus usos y su entorno, claves para la articulación de la propuesta y el proyecto, así como la gestión de su valorización.

Por una parte, nos referimos a los estudios históricos, a las excavaciones arqueológicas, a las memorias y resultados, y a los levantamientos planimétricos, topográficos y fotogramétricos. Para el desarrollo de esta propuesta ha sido igualmente importante el análisis y cuantificación de las causas de degradación, que han sido evaluadas, ya que estos testimonios tamudenses tienen el handicap de ser estructuras muy arrasadas, con un alto riesgo de deterioro (biológico o antrópico) y especialmente sensibles a la erosión mediante el agua de lluvia y su estancamiento, por lo que la protección y drenaje de estos bienes ha sido una motivación importante a la hora de redactar esta propuesta. Se ha estudiado igualmente de forma detallada la acción erosiva de los vientos dominantes sobre el edificio. Especial atención se ha prestado al viento de levante, bien conocido a ambos lados del estrecho, y que ha influido en el diseño de la solución de cubierta propuesta, que incluye la implantación de una pantalla protectora que constituye un elemento importante visual, un sistema anti-viento y un focalizador para su contemplación. No se ha detectado contaminación atmosférica que afecte al inmueble, ni riesgos serios de vandalismo (en la actualidad el yacimiento está cerrado y vigilado), si bien se ha observado una evolución urbanística descontrolada en su entorno que tendría que encauzarse debidamente desde un punto de vista ambiental, paisajístico, visual y de accesibilidad. Al tratarse de un anteproyecto la propuesta que presentamos, queda pendiente en último lugar el desarrollo de estudios constructivos y de materiales previamente a la redacción del proyecto definitivo, así como análisis sismológicos o geotécnicos de cara a garantizar la estabilidad de las estructuras a incorporar. Igualmente se deberán someter a análisis químicos los ladrillos y pavimentos hidráulicos para maximizar su durabilidad y compatibilidad. Y se estudiarán los sistemas de fijación del color y textura de las superficies.

En lo que respecta al proceso de obras, para el desarrollo de la intervención de valorización del edifi- 
cio termal se deberá colocar una cubierta provisional ligera para permitir los trabajos arqueológicos finales y la optimización de los trabajos de conservación sin que afecte al bien. Se deberán entibar las zonas inestables como las salas con hipocausis, la piscina del caldarium, etc. De cara a los recrecidos, consolidaciones y restauraciones se usarán las dosificaciones de morteros emanadas de los análisis previos para asegurar su compatibilidad, evitando el uso de componentes o aditivos que puedan afectar al color o textura de los materiales, así como a su compatibilidad. Se procederá a la consolidación de la fábrica de los muros y arcos del hypocaustum, así como los pavimentos de opus signinum, canalizaciones y otros elementos hidráulicos, fijación de suelos de tierra, procurando conservar sus formas y texturas. Se recrecerá la coronación de muros inestables y otros elementos imprescindibles con hiladas de sacrificio, señalizando claramente su cronología, siempre con el objetivo de garantizar la conservación de las estructuras, la lectura de las preexistencias y se evitarán soluciones miméticas.

Se implantará un sistema de drenaje del entorno e interior del balneum para impedir la entrada de aguas de escorrentías y, en su caso, las freáticas. Se protegerán taludes y perfiles. Entre los sistemas que consideramos ideales señalamos dos: tablestacado y trasdosado con material inerte o colocación de gaviones como arriostramiento. En su caso, no se descarta el uso combinado de ambos sistemas. Se realizarán restituciones didácticas para una mejor interpretación del inmueble, basadas en las propuestas aquí presentadas. Serán arqueológicamente definidas con metodología de anaparástasis constructiva, inequívocamente identificables y compatibles con los restos. Se propone la recreación del vértice suroeste del hypocaustum del ambiente 1, y la parte anexa de la bañera, la restitución de los elementos significativos del apodyterium/frigidarium (porciones de banco, lavapiés, fistula aquaria, canalizaciones y desagües), y los elementos constatados del horno principal: el praefurnium.

\section{Propuesta arquitectónica de la cubierta protectora del balneum}

Respecto a la cobertura de los yacimientos arqueológicos, hay que dejar constancia de que, en muchos casos, se constituye en la medida protectora más eficaz de conservación preventiva de la materialidad. Obviamente, la "encapsulación" arquitectónica de yacimientos no puede generalizarse en conjuntos extensivos de gran tamaño. El alto coste de construcción y mantenimiento, las alteraciones inevitables para su implantación, así como el impacto visual y ambiental, desaconsejan su uso generalizado. Sin embargo, se trata de una medida especialmente recomendable en yacimientos amplios con partes concretas de carácter frágil, en los cuales se evalúen riesgos que sean de una agresividad y envergadura importantes. También, en el ámbito de la difusión, puede ser aconsejable la creación de estructuras y espacios arquitectónicos cualificados y adaptados para estas funciones, y si se plantean de forma conjunta y compatible, aún más positivas. Por otra parte, representan un punto de refugio frente al sol y a la lluvia en un circuito de visitas extenso como el que contamos. Estas necesidades de cobertura y de apoyo a la difusión se dan en el caso del balneum oriental de Tamuda, cuyo análisis arqueológico y de conservación se ha detallado en líneas anteriores.

Podemos decir que un balneum es un "artefacto" arquitectónico implantado para satisfacer necesidades materiales y culturales de un grupo, en este caso la tropa del castellum, que merece una atención especial en cuanto a su conservación. Se trata de restos de una estructura de tamaño asequible $y$, además, de una complejidad técnica, material y funcional reseñable para la época en que se construyó, por lo que dispone de un considerable interés a nivel didáctico, en especial si contamos con el sustento de estudios detallados como el que llevamos a cabo en este trabajo.

A la hora de decidir el tipo de techumbre, no podemos obviar la compleja cuestión de las cubiertas arquitectónicas en los yacimientos arqueológicos, si bien consideramos una cuestión extensa sobre la que no podemos obviar los aspectos que la rigen: la afección a los propios restos (físicos y climáticos), riesgos sobrevenidos, impactos físicos, visuales y ambientales que ofrecen, fragilidad estructural, indecidibilidad de los aspectos estéticos y de diseño (protagonismo, compatibilidad, escala o adaptación), aspectos que deben ser tenidos en cuenta a la hora de realizar una propuesta idónea. En esta, como en otras técnicas de conservación preventiva, no existe una solución "óptima" general ni particular (Fig. 24). Las variables son tantas, objetivas o subjetivas, que resulta imposible satisfacer la totalidad de las exigencias conservativas o las variables estéticas, sustancialmente personales. 


\section{La propuesta arquitectónica de cubierta del balneum oriental tamudense.}

Atendiendo a las reflexiones antes expuestas, aportamos una propuesta a nivel de anteproyecto de la cubierta de protección del balneum oriental de Tamuda, que responde a las siguientes claves.

A nivel conceptual y de diseño, esta propuesta debe resolver un problema: la protección física de un yacimiento arqueológico. Para no manchar el papel mediante una caída irreflexiva en el abismo de las infinitas solu-
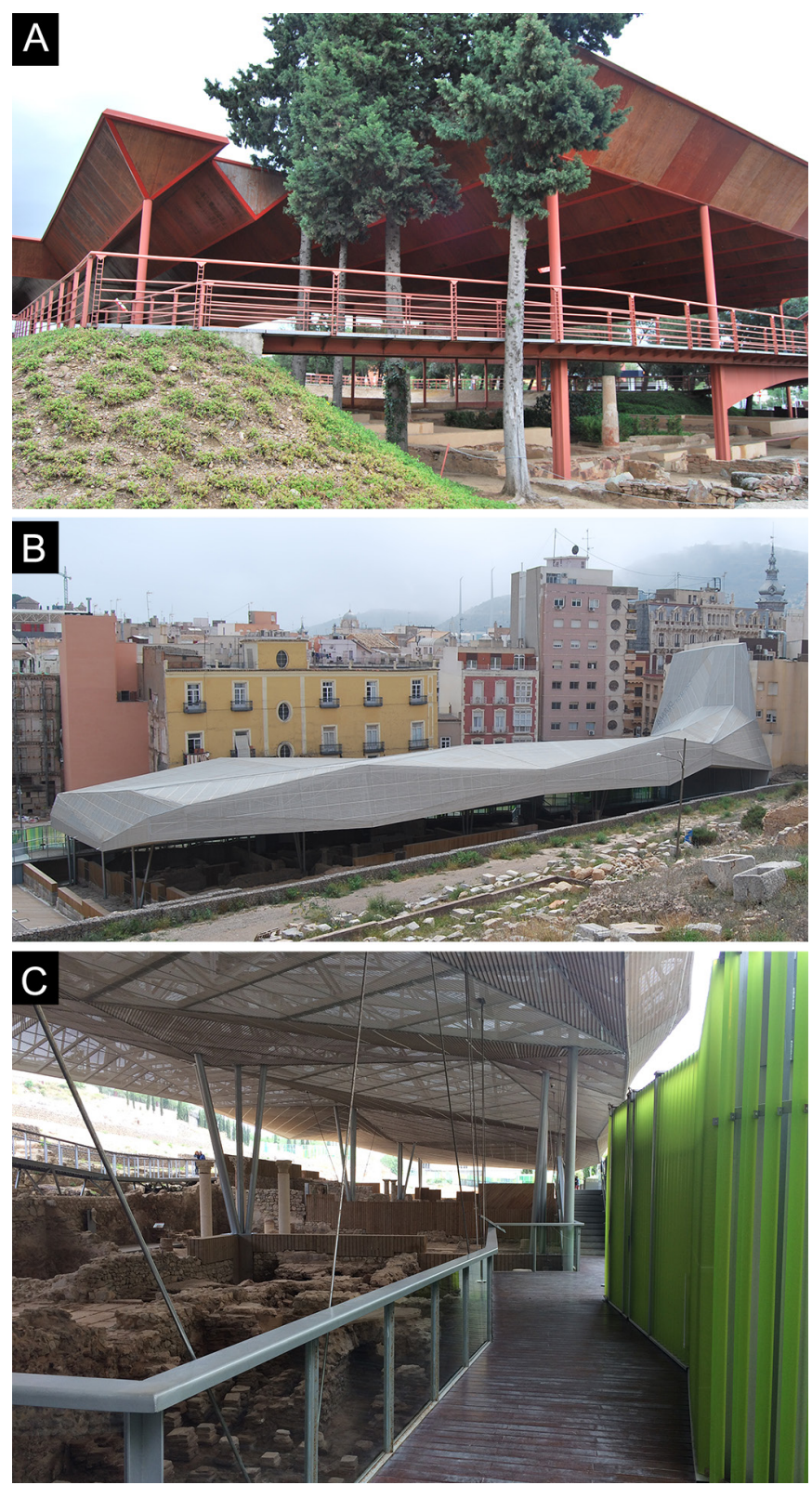

Figura 24. Ejemplos de cubierta de restos arqueológicos: Cubrición de la Casa del Mitreo de Mérida (A), y el Cerro Molinete de Cartagena (B y C). ciones, para sortear la indecidibilidad, cabe recurrir a la "inteligencia intuitiva". Sin embargo, no existe en arquitectura tal "inteligencia intuitiva", que sea ética consigo misma, sin el apoyo del exhaustivo conocimiento del elemento a diseñar a todos los niveles, de una forma holística y a la vez "fractálica", entendiendo el símil matemático como un sistema de análisis-síntesis recurrente e interrelacionado a todos los niveles de metalenguaje, de significados, de escala temporal y espacial. Este es el motivo de la exposición del proceso, realmente sintético y escueto que hemos hecho.

En lo que respecta a los fundamentos proyectuales, nos basamos en el respeto a las preexistencias, al conjunto y al paisaje, pero sin incluir necesariamente mímesis ni camuflaje; facilitando la posibilidad de interpretación y legibilidad del inmueble a nivel de individuo, de sociedad local y de sociedad "ecuménica". En este sentido diríamos que es una cubierta... y lo parece; ya que se ha huido conscientemente de alardes tecnológicos que pudieran competir con las preexistencias arqueológicas del balneum, el conjunto y el paisaje.

A nivel conceptual, formal y funcional, la cubierta del balneum parte de la sencillez formal pero expresiva de su función; como antes se ha dicho, la forma exterior se percibe como lo que es, una cubierta abierta, sin cerramiento (Fig. 25); la forma en diente de sierra es sugerida por el perfil de las montañas y de la línea de cielo; el sistema de soportes se ha diseñado, en su distribución y forma, para minimizar las posibles afecciones a los restos causadas por la cimentación; la sencillez formal del diseño de la cubierta se mitiga con el quiebro curvo entre la parte delantera y trasera, completado con una celosía al estilo local (Fig. 26), que rompe la continuidad de los paños y aporta una fuente de iluminación natural, cenital y contrastante; como mirador se ha procurado otorgarle al techo, en su formalización, una cualidad como elemento focalizador, tanto hacia los restos del balneum, como al conjunto y al paisaje circundante; el muro del fondo, además de respaldar la estructura como contrafuerte en el límite del yacimiento, es un elemento focalizador más y una barrera contra el viento (Fig. 27); la plataforma-mirador interior tiene un diseño que resalta su ligereza y que no compite con la arqueología, pero la ayuda desde el punto de vista didáctico; la rampa curva de acceso al mirador, además de constituirse en una suerte de camino iniciático hacia los restos, es elemento de accesibilidad para discapacitados en el circuito propuesto, una novedad en este yacimiento (Fig. 28). 


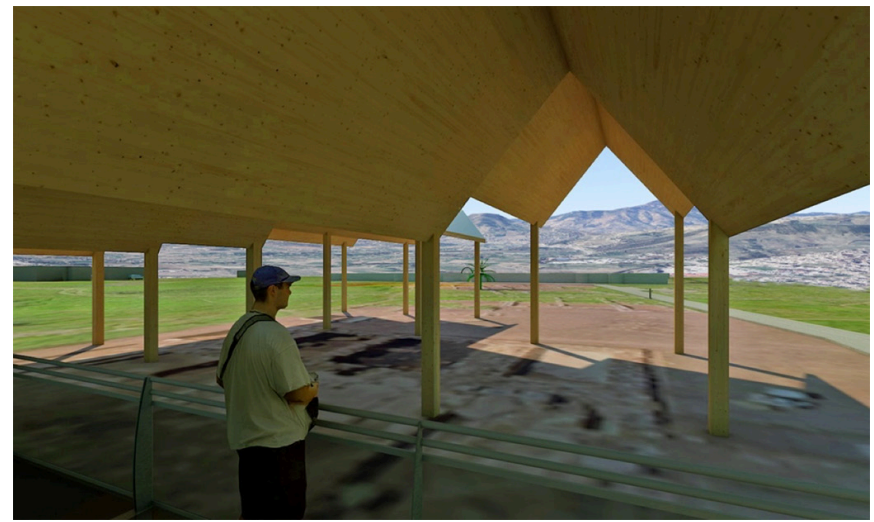

Figura 25. Cubierta del balneum. Vista hacia el oeste desde pasarela de observación y contemplación de los restos, el conjunto y el paisaje.

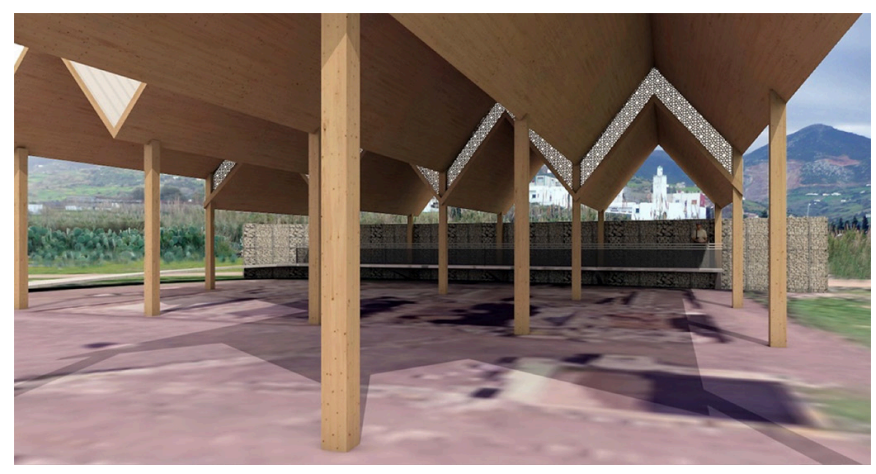

Figura 26. Cubierta del balneum. Vista del interior hacia el este y del paisaje de fondo.

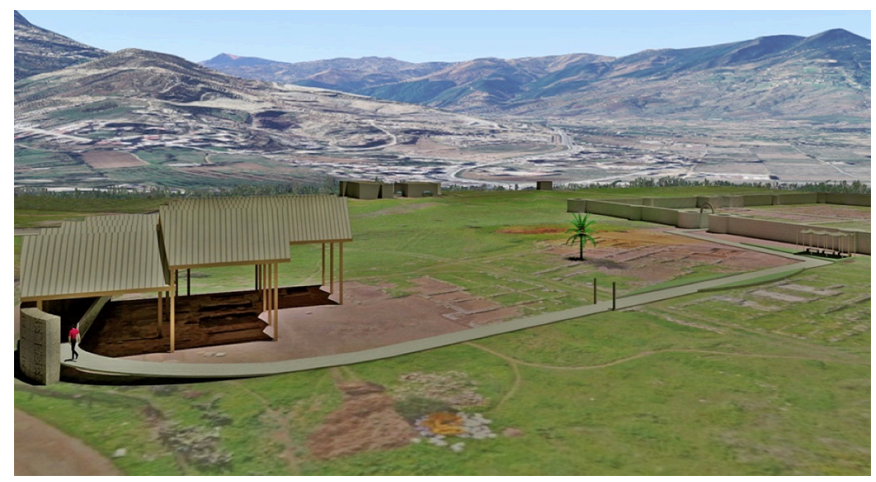

Figura 27. Cubierta del balneum. Vista general hacia el oeste. Muro de respaldo y de protección contra el viento. Integración con la línea del cielo y el paisaje.

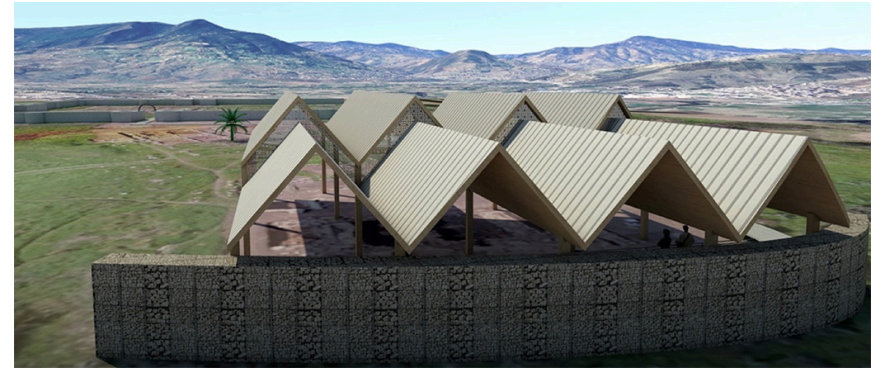

Figura 28. Cubierta del balneum. Vista hacia el sur, al conjunto y al paisaje.
En lo que respecta al sistema constructivo y a los materiales, debemos apuntar que en el diseño ha primado la sencillez constructiva y la pedagogía de lo artesano, sin estridencias tecnológicas; la techumbre y los soportes se plantean con una estructura de perfiles de acero galvanizado y un forrado de madera protegida y barnizada; cimentación por dados de hormigón armado y excavación con control arqueológico presencial; el exterior de la techumbre será, por ligereza, de chapa de aluminio prelacado, con perfil similar a una cubierta de tégulas; para las dos secciones de la cubierta, delantera y trasera, se decidirán dos colores acordes entre sí y con el entorno; el muro trasero será a base de gaviones de piedra local con colores y texturas a decidir en obra; la rampa de acceso y la plataforma-mirador se realizarán con perfiles y rejilla metálica industrial de acero galvanizado, y los antepechos de vidrio laminado; incorporándose el sistema adecuado de desagües para evitar daños al yacimiento.

A nivel didáctico, en aplicación al balneum y a su puesta en valor, ya nos hemos referido a las cualidades del edificio como construcción singular y tecnológicamente compleja para su época, de manera que los sistemas hidráulico y calefactor, sus conexiones y relaciones técnicas, en unión con el particular funcionamiento orgánico y social, hacen de estos baños para la tropa romana un edificio que es conveniente y necesario explicar. Esto lo encomendamos a tres métodos clásicos: en primer lugar, a la visión de los restos emergentes del balneum, desde la plataforma-mirador, elevada para facilitar la lectura; en segundo lugar, a las restituciones didácticas de los principales elementos del edificio, tomando como base las reconstrucciones volumétricas que ya se han definido en apartados anteriores; y en último lugar, se plantea la exposición de textos y gráficos explicativos formados por atriles con información, gráfica y escrita, condensada y de rápida lectura, adaptada para disminuidos visuales. Para descripciones más detalladas, se reserva la posible instalación de pantallas audiovisuales en el intradós del muro de resguardo o la inclusión de enlaces a través de códigos QR de informaciones accesibles mediante el móvil.

\section{CONCLUSIONES: CONOCER PARA CON- SERVAR Y DIFUNDIR}

Para poder realizar la puesta en valor del balneum oriental de Tamuda debíamos completar el estudio integral de los elementos arquitectónicos que lo componen, de 
manera que resultaba imprescindible acercarnos a la articulación exterior e interior del edificio para poder dar los primeros pasos hacia una correcta preservación y difusión. En este trabajo hemos presentado de forma detallada todos los resultados del estudio arqueo-arquitectónico acometido por el equipo marroco-español, utilizando todas las técnicas a nuestro alcance que pudieran servir de apoyo a este planteamiento. Ahora sabemos que el balneum del barrio oriental de Tamuda es un edificio coherente con la articulación del asentamiento, y afín a otros espacios campamentales análogos. Su ubicación estratégica junto al río, su disposición segregada pero no ajena al castellum, y su articulación interior sencilla y austera pero completa, sitúa a este balneum en conexión directa con otros equipamientos análogos de la Tingitana (ya hemos referido las afinidades con los baños iniciales de Thamusida) y de otras localizaciones del limes como Vindolanda o Malaiesti, que parecen responder a una planificación predeterminada o que al menos atienden a unos patrones similares. Observamos en el balneum tetuaní la aplicación de técnicas difundidas en esta misma área regional, como los acabados de los sistemas de concamerationes en asociación con techumbres "armchair voussoir"; así como una vertebración interior que responde a las mismas necesidades de otros baños presentes en ambiente campamental, con unos acabados sencillos, traducidos en la ausencia de espacios absidiales o soluciones arquitectónicas complejas; y un circuito de usos lineal, que ofrece como resultado un edificio monolítico pero que responde correctamente a las necesidades higiénicas y de ocio de los destacamentos allí acantonados y de los integrantes de las cannabae.

El estudio del edificio termal aquí presentado y el de los otros equipamientos documentados en el barrio oriental tamudense, favorecen la interpretación de considerar el espacio externo al castellum como un ambiente perimetral al campamento militar muy activo y tremendamente dinámico, que supera lo previsible inicialmente. Sobre estas bases, de un conocimiento profundo del edificio al que nos enfrentamos y del resto del barrio oriental tamudense, se ha trazado una propuesta de conservación y preservación orientada a su fácil comprensión y a su difusión, y que comprende, respeta y valora su funcionalidad original y su finalidad actual. Solo desde un estudio multidisciplinar es posible un trabajo integrado, donde arqueólogos, arquitectos, conservadores del patrimonio y técnicos especialistas aúnan esfuerzos para que el conocimiento del bien sea la base para su valorización.

\section{AGRADECIMIENTOS}

Queremos dejar constancia de nuestro agradecimiento al personal del Yacimiento Arqueológico de Tamuda y al Ministerio de Cultura del Reino de Marruecos por las autorizaciones pertinentes y las facilidades prestadas para el desarrollo del proyecto de investigación en el que se inscribe este estudio; especialmente al INSAP y la Direction du Patrimoine, con la cual la Universidad de Cádiz ha mantenido un Convenio de Colaboración durante los últimos seis años. Igualmente, debemos destacar el inestimable trabajo realizado por M. ${ }^{\mathrm{a}}$ Cristina Gómez Bueno de cara a la generación del modelado 3D de este balneum oriental de Tamuda, y su disposición para la continua mejora e incorporación de nuevas actualizaciones en el citado levantamiento. Por otra parte, es igualmente necesario reconocer la generosa labor del personal técnico del Laboratorio de Prehistoria y Arqueología de la Universidad de Cádiz (Labap-UCA), cuya asistencia técnica en topografía y la documentación mediante vuelos de RPAS-drone ha revertido positivamente en este estudio.

\section{FUENTES INÉDITAS}

Verdugo, J. y Ramón Girón, F.J., 2018: “Un baño para la tropa: una propuesta de puesta en valor del balneum de Tamuda", en D. Bernal-Casasola, (dir.) Memoria cientifica del proyecto Economía y artesanado en Tamuda (Tetuán). Épocas mauritana y romana. Ayudas a Proyectos en el Exterior, anualidad 2017), pp. 59-128. (Memoria final inédita).

\section{BIBLIOGRAFÍA}

Asensio, J. A., Magallón, M. ${ }^{\text {a }}$ A. y Sillières, P. 2016: La ciudad romana de Labitolosa: el conjunto arqueológico del cerro Calvario (La Puebla de Castro, Huesca) en la Antigüedad y la Edad Media. Instituto de Estudios Altoaragoneses, Huesca.

Bermejo, J., Robles, S., Toscano, C. y Campos, J. M. 2015: Aqua Militaria: captación, almacenamiento y distribución del agua en Tamuda, en J. Campos y J. Bermejo (eds.) El urbanismo militar del castellum de Tamuda: La castramentación interior, pp. 111-140. L'Erma di Bretschneider, Roma. Bernal-Casasola, D., Bustamante, M., Díaz, J. J., Expósito, J. A. y Moujoud, T. 2018a: "Tamuda revisitada: De la primera destrucción ¿sertoriana? al foso del Castellum (2014-2018)”, Antiquités Africaines, 54, pp. 53-84. https://doi.org/10.4000/antafr.817

Bernal-Casasola, D., Díaz, J. J., Expósito, J. A., Bustamante, M., Retamosa, J., Portillo, J. L., Pascual, M. A., Lara, M., Vargas, J. M. y Ghottes, M. 2019: "Gaditanos en Tamuda. Indicadores comerciales entre la bahía de Cádiz y la Tingitana Mediterránea (ss. I a.C.- I d.C.)”, en J. Ramos, M. Otte y E. Vijande (eds.) Les Migrations entre Méditerranée et terre promise. Ocupaciones de la region geohistórica del estrecho de Gibraltar por sociedades prehistóricas y de la antigüedad. Movilidades de población, relaciones y contactos, vol. 1, pp. 185-205. Editorial UCA, Sanlúcar de Barrameda.

Bernal-Casasola, D., Hoyo, J. de, Domínguez-Bella, S., Ghottes, M., Raissouni, B., Expósito, J. A., Vargas, J. M., Díaz, J. J., Lara, M., Bustamante, M., Pascual, M. A. y Moujoud, T. 2016: "Inscripción conmemorativa y 
sellos latericios del Balneum Oriental de Tamuda", Bulletin d'Archéologie Marocaine, 23,1, pp. 139-156.

Bernal-Casasola, D., Hoyo, J. de y Ghottes, M. 2018b: "Fugatis ho[stibus]. Nouvelle inscription commémorative du castellum de Tamuda (Maurétanie Tingitane)", Zeitschrift für Papyrologie und Epigraphik, 205, pp. 291-296.

Bernard, G. 2020: “ Une nouvelle inscription de Tamuda et le contexte militaro-politique de la province de Maurétanie Tingitane", Antiquités Africaines, 56, pp. 345-355.

Bidwell, P. 1997: Roman Forts in Britain. English Heritage, London.

Bouet, A. 1999: Les matériaux de construction en terre cuite dans les thermes de la Gaule Narbonnaise. Ausonius Éditions, Pessac.

Bustamante, M., Raissouni, B., Bernal-Casasola, D., Vargas, J. M. y Moreno, E. 2013: "Intervención en la Porta Praetoria del castellum de Tamuda. Resultados del Sondeo 5", en D. Bernal-Casasola, B. Raissouni, J. Verdugo y M. Zouak (eds.), Tamuda. Cronosecuencia de la ciudad mauritana y del castellum romano, pp. 317-347. Universidad de Cádiz, Cádiz.

Campbell, D. B. 2009: Roman Auxiliary Forts 27 BC-AD 378. Oshprey Publishing, Oxford.

Camporeale, S. 2008: "Materiali e tecniche delle costruzioni", en A. Akerraz y E. Papi (dir.), Sidi Ali Ben Ahmed-Thamusida, Vol 1, I contesti, pp. 62178. Quasar, Roma.

Campos, J., Bermejo, J., Fernández, L., Gómez, A., Ruiz, J. y Ghottes, M. 2012: "El balneum del castellum de Tamuda. Análisis arqueoarquitectónico y arqueológico", en M. B. Cocco, A. Gabini y A. Ibba (dirs.), L'Africa Romana XIX, Transformazione dei paesaggi del potere nell'Africa settentrionale fino a la fine del mondo antico, pp. 2429-2442. Carocci editore, Roma.

Darby, R. 2015: "The Late Roman military baths of the Wadi Arabah: a survey of recent archaeological work", Syria, 92, pp. 67-83. https://doi. org/10.4000/syria.3194

Degbomont, J. M. 1984: Le chauffage par hypocauste dan's l'hábitat privé. De la place St-Lambert à Liège à l'Aula Palatina de Trèves, Études et Recherches Archéologiques de l'Université de Liège, 17. Lieja.

Euzennat, M. 1989: Le limes de Tingitane. La frontière méridionale. Études D’Antiquités Africaines, Éditions CNRS. París.

Fernández, L., Bermejo, J., Campos, J. M., Verdugo, J. y Ghottes, M. 2015: "El balneum de la via praetoria: una instalación terapéutica en el castellum de Tamuda", en J. M. Campos y J. Bermejo (eds.), El urbanismo militar del castellum de Tamuda: La castramentación interior, pp. 175-209. L'Erma di Bretschneider, Roma.

García-Entero, V. 2005: Los balnea domésticos -ámbito rural y urbano-en la Hispania romana, Anejos de Archivo Español de Arqueología XXXVII. CSIC, Madrid.

Gros, P. 1996: L'Architecture romaine du début du IIIe siècle av. J. -C. à la fin du Haut-Empire. 1. Les monuments publics. Paris.

Gros, P. y Torelli, M. 1994: Storia dell'urbanistica. Il mondo romano. Ed. Laterza, Roma-Bari.

Keppie, L. J. F. 1981: "Excavation of a Roman Bathhouse at Bothwellhaugh, 1975-76", Glasgow Archaeological Journal, 8, pp. 46-94. https://doi. org/10.3366/gas.1981.8.8.46

Krencker, D., Krüger, E., Lehmann, H. y Wachtler, H. 1929: Die trierer Kaiserthermen I. Dr. Benno Filser Verlag, Ausgburg.

Lancaster, L. C. 2015a: Innovative Vaulting in the Architecture of the Roman Empire. $1^{\text {st }}$ to $4^{\text {th }}$ Centuries CE. Cambridge University Press. New York.
Lancaster, L.C. 2015b: "Armchair voussoir vaults in bath buildings of the Western Roman Empire”, en B. Bowen, D. Friedman, Th. Leslie y J. Ochsendorf (eds.), Proceedings of the $5^{\text {th }}$ International Congress on Construction History, vol. 2, pp. 457-465. The Construction History Society of America, Chicago.

Maréchal, S. 2012: "Research on Roman bathing: old models and new ideas", Revue belge de Philologie et d'Historie, 91.1, pp. 143-164. https://doi. org/10.3406/rbph.2012.8393

Morán, C. y Giménez, C. 1948: Excavaciones en Tamuda 1946. Relación de las Memorias publicadas por la Junta Superior de Monumentos Históricos y Artísticos, 10. Madrid.

Morillo, A. y Salido, J. 2011: "Labra de época romana en Hispania", Archivo Español de Arqueología, 84, pp. 153-178. https://doi.org/10.3989/ aespa.084.011.006

Nielsen, I. 1993: Thermae et balnea. The architecture and cultural history of Roman Public Baths. Aarhus University Press, Aarhus.

Perea, S. 1997: "Baños para soldados y el culto de Fortuna", en M. J. Pérez (ed.), Termalismo Antiguo (I Congreso Peninsular. Actas). pp. 149-167. UNED, Madrid.

Quintero, P. 1941: Excavaciones en Tamuda. Memoria Resumen de las practicadas en 1940. Relación de las Memorias publicadas por la Junta Superior de Monumentos Históricos y Artísticos, 2. Larache.

Quintero, P. y Giménez, C. 1945: Excavaciones en Tamuda. Memoria resumen de las practicadas en 1944. Relación de las Memorias publicadas por la Junta Superior de Monumentos Históricos y Artísticos, 8. Tetuán.

Rebuffat, R., Hallier, G. y Marion, J. 1970: Thamusida II. Fouilles du Servide des Antiquités du Maroc, Mélanges D’Archéologie et d'Histoire, 2. École Française de Roma, Roma.

Reis, M. P. 2004: Las termas y balnea romanos de lusitana, Stvdia Lvsitana, 1. Ministerio de Cultura, Madrid.

Roldán, L. y Bustamante, M. 2016: "Desde las figlinae a los edificios: el uso del barro cocido en el sur de la Baetica", Arqueología de la Arquitectura, 13, e047. https://doi.org/10.3989/arq.arqt.2016.165

Rusu, I., Radu, C., Tentea, O., Popescu, O. y Kelemen, B. 2019: “A probable case of infantile cortical hiperostosis in 2nd-4th centuries AD Romania", International Journal of Paleopathology, 26, pp. 8-13. https://doi. org/10.1016/j.ijpp.2019.05.004

Sommer, C. S. 1984: The Military Vici in Roman Britain. Aspects of their Origin, their Location and Layout, Administration, Function and End. British Archaeological Reports, Series 129. Oxford.

Tentea, O. 2018: "Baths and bathing in Dacia under Trajan", en S. Sommer y S. Matesic (dirs.), Limes XXIII. Proceedings of the $23^{\text {th }}$ International Congress of Roman Frontier Studies, pp. 133-137. Nünnerich-Asmus Verlag, Mainz.

Tentea, O. y Burkhardt, B. 2017: The baths on the frontiers of Roman Dacia. Mega, Bucarest.

Vega, T. 2010: "Novedades sobre las termas legionarias en Britannia", en Las técnicas y las construcciones en la Ingeniería Romana, V Congreso de las Obras Públicas Romanas. Fundación de la Ingeniería técnica de obras públicas, Madrid.

Villaverde, N. 2001: Tingitana en la Antigüedad Tardia (siglos III-VII). Autoctonía y romanidad en el extremo occidente mediterráneo. Real Academia de la Historia, Madrid. 